\title{
A Strategic Decision Framework for a Sustainable Wastewater Treatment and Management in the Oil Producing Region
}

\author{
Idris Abdullahi Hashim ${ }^{1} \quad$ Mansur Hamma-adama ${ }^{2}$ Suresh Surendran ${ }^{3}$ \\ 1.Department of Petroleum Engineering, Robert Gordon University, Aberdeen, United Kingdom \\ 2.Department of Civil Engineering, Kaduna Polytechnic, Kaduna Nigeria \\ 3.Department of Civil and Environmental Engineering, Coventry University, United Kingdom \\ E-mail: i.hashim@rgu.ac.uk; mansurhamma@kadunapolytechnic.edu.ng
}

\begin{abstract}
The study aimed to investigate how managing the growing water demand and wastewater production by treating and reclaiming Water from the Wastewater in Delta State. Mainly to carry out a comparative feasibility study and develop a decision support system (DSS) or strategy/planning framework for a sustainable alternative for water/wastewater treatment and management in oil \& gas industries, Water, wastewater industries and authorities in Delta State. Data was collected using a mixed approach. Primary data was collected using semistructured interviews and closed-ended questionnaire survey. Descriptive analysis was applied in analysing the questionnaires, and thematic analysis was used in analysing the interviews. It was concluded that a centralised system is required to collect rainwater and wastewater, and recycle Water in Delta state for reuse, and reduce dependence on freshwater. It will be an improvement to the direct collection of wastewater from individual houses by private waste management organisations that drain the sewage systems. It was found that causes of water and wastewater problems in Delta State, Nigeria include: government regulation; financial problem; lack of sufficient land for development; pollution; high population; using potable Water for non-potable use; water shortage; poor technology; lack of people's awareness on water, and poor maintenance. Based on this, grey water reuse, decentralised system of water reclamation and education and awareness of wastewater management were recommended to solve the water and wastewater problems found in the state. Microscale solutions such as ponds, permeable pavements, rain gardens, rainwater harvesting systems, wetlands, and green roofs were recommended. In addition to the recommendations, a strategic framework/decision support system for sustainable alternatives for oil, gas, water and wastewater industries and authorities was developed.
\end{abstract}

Keywords: Framework, Graywater, Management, Pollution, Water, Wastewater

DOI: $10.7176 / \mathrm{CER} / 12-8-04$

Publication date:August $31^{\text {st }} 2020$

\section{Introduction}

According to Angelakis and Snyder (2015), wastewater treatment and management had been in existence before the categorisation of causes of wastewater. The treatment and management of wastewater in order to make valuable reuse of it have evolved and advanced over the years. Nigeria is facing a severe problem of managing waste and Wastewater (Omenka 2010, 2012). The water waste and wastewater management problem is more peculiar in oil, producing rich States like Delta State. Most citizens in Nigeria feel that it is the responsibility of the government to handle waste, so they indiscriminately dispose of it (Izonfuo et al. 2013). Due to oil and gas production activities in the Delta State of Nigeria, oil spillages, among other problems affecting groundwater is inevitable (Onojake 2012). For this reason, a sustainable alternative to the current wastewater treatment and management in the Delta State is an essential subject to research for implementation. Wastewater is collected in Asaba and its environs through a centralised facility, designed with wastewater treatment (Izonfuo et al. 2013). This facility is characterised by inefficient wastewater collection and improper waste management method, leading to water shortage, and inadequate treatment of wastewater for reuse (Omenka 2010). This research focuses on investigating how the wastewater is treated and to propose a sustainable alternative method.

The idea of wastewater treatment and management in Delta State is useful for water re-usability due to the growing increase in water demand as compared to water availability in the region. This study seeks to address this by developing economically profitable means of implementing sustainable technology to contribute to the realisation of a circular economy. This study aims to develop a strategy/policy framework or DSS through investigating how managing the growing water demand and wastewater production by treating and reclaiming Water from the Wastewater in Delta State. Thus, the objectives include the development of a detailed feasibility study on the following areas: Feasibility study on the development of water/wastewater reclamation (treatment and purification) processes and technologies particularly water reclamation from oil and gas activities; Feasibility study on the development of energy and nutrient recovery from water and wastewater treatment processes and technologies; Feasibility study on the development of decentralised but integrated water-energynutrient reclamation (from oil and gas activities as decentralised treatment/recovery) system that help close cycles in ways to contribute to the environmental, social/health safety and economic benefits of the Delta. 


\section{Literature Review}

Delta State is located in Nigeria, West Africa. Nigeria has a landmass of $923,800 \mathrm{~km}^{2}$ with a population of over 150 million (Federal Republic of Nigeria 2003). The temperature is between $27^{\circ} \mathrm{C}$ to $32^{\circ} \mathrm{C}$, and the annual rainfall for coastal areas is $3500 \mathrm{~mm}$ while the northern region has yearly precipitation of $600 \mathrm{~mm}$ (Federal Republic of Nigeria 2003). Delta State is one of 36 States in Nigeria; it has a land area of $762 \mathrm{~km}^{2}$. The capital of Delta is Asaba, and it houses the State's water treatment Corporation, Delta State Urban Water Board.

Water contamination from crude oil refinery activities is regarded as one of the most common causes of Wastewater (Bahadori 2014). In the oil-rich regions, it is recorded that over 14 billion bbl. Water is produced from oil and gas activities which are considered as waste (Reynolds 2003; Veil et al. 2004). For this reason, the quest for the broader reuse of wastewater through adequate treatment and management is increasingly becoming popular; especially in some European countries where there are water crises due to pollution, scarcity and floods (Water News Europe 2017). According to Water News Europe (2017), a significant barrier to achieving sustainable wastewater treatment and management is the lack of a clear and comprehensive legislative agenda in the region where reuse of wastewater is paramount to existence. In oil-rich Saudi Arabia, the government is committed to a policy of complete re-usability of wastewater. This policy has helped the country in making use of supposed wastewater for industrial, domestic and agricultural usage through proper treatment and management policy. With the application of variation of water treatment techniques, the county is meeting almost 10 per cent of its water demand through reuse of wastewater caused by oil and gas activities (Abu-Zeid 1998).

According to Onabolu et al. (2011), only 47\% of individuals living in rural areas have access to clean Water in Nigeria, and $72 \%$ of urban dwellers. Akali et al. (2014) conducted a physical assessment of the water supply in Nigeria. They found a breakdown of systems due to the lack and improper operations and maintenance, leading to the dependence of individuals on wells, rivers, streams, and other sources of untreated Water, all of which are affected by the activities of oil and gas companies. For this reason, the study seeks to investigate how managing the growing water demand and wastewater production by treating and reclaiming Water from the Wastewater in Delta State.

According to Idris-Nda et al. (2013), it is necessary to manage sources of Water, to aid in its treatment, use and reuse. An improperly managed water system has the potential to negatively impact on the natural environment, on human health as domestic wastewater contains disease-producing micro-organism and chemicals and on the economic environment. Komolafe et al. (2009) suggest the efficient maintenance of policies and culture, human resources development, power supply, security, and continuity improve water supply systems in Nigeria.

\subsection{Water, Wastewater, Grey Water, and other Alternative Sources of Water}

Wastewater is defined by Sonune and Ghate (2004) as wastes of community life that are represented by waterborne solids and liquid. It includes "putrescible" or biologically decomposable organic solids. Sonune and Ghate (2004) and Idris-Nda et al. (2013) agree on the facts that wastewater could result from domestic, industrial, and agricultural. However, the pathogens residing in the Water finds their way to humans through contaminated drinking water or food.

On the other hand, Greywater results from domestic activities such as laundry, sinks, hand basin, bathing and kitchen (Dallas and Ho 2005; Widiastuti et al. 2008). It can be discharged in both open and closed drains, and usually ends up in streams, rivers, or worse still, behind homes until it either evaporates or percolates (Winward et al. 2008). Therefore, the area becomes breeding grounds for mosquitoes and other disease agents (Mah et al. 2009). Hoek (2004), however, categorises both as wastewater in the definition of wastewater.

Sonune and Ghate (2004) argue for the treatment of wastewater, stating that the process involves the decomposition and partial removal and change of solids in wastewater. Idris-Nda et al. (2013) also recommend wastewater treatment and reuse, as a complement for water use, and a reduction strategy for disaster risk, and over-reliance on fresh and potable Water. Wastewater can also serve several purposes when reused, such as fish farming, aquifer recharge, irrigation, and fire protection Emigilati, et al. (2015). However, Badejo et al. (2015) also add that many world cultures find wastewater to be a nuisance, mostly due to the hazards it possesses to human health. However, Mahmood and Maqbool (2006) conclude that wastewater is still a resource, though both advantageous and inconveniencing in its use.

\subsection{Impact of Oil and Gas Activities on Water in Delta State}

According to Onabolu et al. (2010), the Nigerian people are faced with a serious problem caused by inadequate access to safe drinking water, as only half of the Nigerian population have access to improved water sources. Similar to other African countries, Badejo et al. (2015) found that it is common practice in Nigeria to buy Water from vendors, invest in wells, storage tanks, and boreholes. It is also common practice to use a combination of these sources (Badejo et al. 2015). 
$58 \%$ of rural Nigeria does not have access to piped Water, and the scenarios where it is available, Adekalu et al. (2002) find that it is irregular resulting from poor infrastructures and deterioration of the schemes available. According to Onabolu (2011), the household taps in the rural areas are not fully reticulated to the decentralised water supply systems, requiring the residents to source water from streams and rivers. According to Ekiye and Zeijao (2010), the major cause of water pollution in Nigeria, especially Delta state, is industrial effluence, especially from oil and gas activities.

Idu (2015) states that the industrial effluents are discharged into Water directly, without prior treatment, or indirectly, and can increase water quality parameters. According to Idu (2015), 10\% or less of Nigerian's oil firms treat their effluents before being discharged into the rivers. Ahmed and Tanko (2000), Wakawa et al. (2008) find out that this leads to an increase of inorganic metals such as $\mathrm{Pb}, \mathrm{Cr}$ and $\mathrm{Fe}$ in most water bodies in Nigeria. Furthermore, Idu (2015) finds that the lack of good drainage system in the country has increased the surface water impairment due to erosions during rainfall, and carries pollutants from industries, dumping sites, farmlands, and houses.

Onojake et al. (2012) recommended that adequate treatment, monitoring and reuse for irrigation or as industrial process water plan for produced water in Delta be put in place to ensure compliance with best global practices. Although there has been no reported environmental disaster of high magnitude associated produced water disposal, it is nevertheless a known fact that much of this waste produced Water is dumped in the environment, especially during the drilling operation. A complete treatment system of wastewater may consist of the application of some "physical, chemical and biological processes to the wastewater" (Sadi and Adebitan 2014:12). After the treatment process, however, Olubori (2013) adds that disposal can be achieved using methods such as land application, dilution in streams and rivers, and reuse in aquaculture and crop irrigation.

\subsection{Wastewater Reclamation based on Water, Wastewater, and other Alternative Sources of Water}

A combination of physical unit operation and chemical and biological unit processes are used in treating wastewater in a central segregated location (Paillard et al. 2005). According to Absar (2006), the choice of treatment or management process depends on the environment in question, and but consists of providing an environment in which natural processes of decay can be intensified and controlled, to ensure the process occurs in an objectionable manner.

According to Sadi and Adebitan (2014), water reclamation makes wastewater a resource rather than waste, as Water is a renewable resource and can have economic and environmental benefits when reclaimed. In industrialised societies, water demand is met by the supply of greywater, rainwater, stormwater, and Wastewater (Gleick 2003). According to Domenech (2011), these sustainable alternatives which were once treated as a nuisance, are now valuable resources after reclamation. Stormwater is managed in the USA using an approach called low impact development. In Australia, it is managed using water sensitive urban design. They help in promoting the use of stormwater.

These work with micro-scale solutions such as ponds, permeable pavements, rain gardens, rainwater harvesting systems, wetlands, and green roofs (Brown, 2005). According to UNEP (2009), rainwater harvesting includes storage in ponds and collection of Water from the soil. The collection of rainwater from rooftops is widely used in Australia, Brazil, India, Kenya, and Spain. For instance, Table 1 presents the compiled benefits of reusing rainwater by Domenech (2011). The major problem, however, is the impossibility of predicting availabilities.

Table 1. Benefits of Rainwater Harvesting (Source: Domenech, 2011)

\begin{tabular}{|c|c|c|}
\hline & Direct benefits & Indirect benefits \\
\hline \multirow[t]{4}{*}{$\begin{array}{l}\text { Short } \\
\text { term }\end{array}$} & $\begin{array}{l}\text { Reduced drinking water consumption } \\
\text { High collection and distribution } \\
\text { efficiency. }\end{array}$ & $\begin{array}{l}\text { Reduced pressure on external water sources. } \\
\text { Conservation of water bodies (rivers, aquifers, lakes). } \\
\text { Preservation of aquatic ecosystems. }\end{array}$ \\
\hline & Reduction of flood risk. & $\begin{array}{l}\text { Reduced risk for disadvantaged groups. } \\
\text { Reduced economic losses. }\end{array}$ \\
\hline & Self-sufficiency. & Smaller dependency on distant water sources. \\
\hline & $\begin{array}{l}\text { Major control and awareness of the } \\
\text { water consumed. }\end{array}$ & Enhanced rational use of water. \\
\hline \multirow[t]{4}{*}{$\begin{array}{l}\text { Long } \\
\text { term }\end{array}$} & $\begin{array}{l}\text { Reduction of storm water flows treated } \\
\text { in the wastewater plant. }\end{array}$ & $\begin{array}{l}\text { Reduction of energy consumption. Reduced use of } \\
\text { chemical reagents. Reduction of operation and } \\
\text { maintenance costs of wastewater treatment plants. }\end{array}$ \\
\hline & $\begin{array}{l}\text { Transporting water from far away is less } \\
\text { necessary. }\end{array}$ & $\begin{array}{l}\text { Reduction of energy consumption. Less necessity for } \\
\text { building hydraulic infrastructures (dams, water transfers, } \\
\text { desalination plants). Restoration of the hydrological cycle. }\end{array}$ \\
\hline & Savings in the water bill. & Increased purchasing power. \\
\hline & Reduction of non-point water pollution. & Recuperation of aquatic ecosystems. \\
\hline
\end{tabular}


According to Roy et al. (2008) however, these approaches are affected by cost, insufficient engineering standards, inefficient guidelines, lack of legislative mandate, fragmented responsibilities, resistance to change, lack of institutional capacity, and lack of funding. According to Punmia et al. (2007:36), the wastewater management system should be assessed for risk in terms of cost criteria, cultural criteria, ecological criteria, health criteria, nuisance criteria, operational criteria, and reuse criteria.

Ekiye and Zejiao (2010) further add that treatment is usually in 3 stages: preliminary, primary, and secondary stages. In the initial phase, floating materials, as well as heavy settleable inorganic solids, are removed, leading to the primary treatment aimed at the sedimentation of organic suspended solids. After this stage, biological processes are used to remove most of the organic matter in the secondary or natural treatment stage (Ikomi et al. 2003). Sometimes an advance treatment might be required, where pollutants such as soluble inorganic compounds and other toxic substances not removed in the primary and secondary procedure are removed Armah et al. (2005).

\subsection{Water, Wastewater, and Greywater Recycling Methods}

In Maradi, a city in Niger, Nassartbaye (2011) finds that the increasing population and acceleration in urbanisation have led to increased use of domestic Water, thereby leading to a significant increase in wastewater generated in the city. Konate (2012) find out that the lack of a proper and complete sewerage system leads to the direct discharge of wastewater into the environment. This is similar in Nigeria as well, as some rural cities do not have integrated systems (Adeyemo and Gboyesola 2013; Adogu et al. 2015; Emigilati et al. 2015).

Wang et al. (2013) discuss in further detail the practices for Water and wastewater treatment in African countries, stating that they include on-site treatment, offsite treatment, and conventional treatment. The on-site treatment, according to Wang et al. (2013) involves pit latrines and septic tanks, which Konaté (2012) finds is used in rural parts of Africa and some urban parts as well. Wang et al. (2013) and UNEO (2010) find that the maintenance and management of these systems are reduced, leading to the deterioration of groundwater quality. According to Lipp et al. (2001), these full and overflowing systems are a source of waterborne diseases.

The second method, which is the offsite wastewater treatment system, has also been found by Mara and Alabaster (2008) to be a common practice. According to Wang et al. (2013), the wastewater is collected and transported to sites for treatment. Wang et al. (2013) add that the system is used in countries like Zambia using technology like activated sludge treatment, combined trickling filter plants, and stabilisation ponds. The third method is the conventional treatment using techniques such as activated sludge and biofilms, but is, however, rarely used due to the lack of energy and financial resource (Wang et al. 2013).

According to Psutka et al. (2011), both the centralised and decentralised systems are adopted for water supply in Africa. Wang et al. (2013) explain that the centralised system involves the collection, treatment, and distribution of raw Water by a pipeline network, and is treated using methods such as coagulation, filtration, and disinfection in few African countries. The decentralised system, on the other hand, includes abstracting Water from an underground borehole or mobile truck, or the selling of water house to house by a water vendor, which is the case in most African countries because some cities lack pipelines.

\subsection{Energy and Nutrient Recovery from Wastewater}

As earlier stated, wastewater is a resource (Ajibade 2004). According to Nkonyeasya (2010), depending on the type of activity producing the wastewater, its composition varies. Nkonyeasya (2010) finds that with all these constituents, wastewater is a valuable energy source.

Wastewater is also useful in agriculture (Olaleye and Adediji, 2005). Many industrialised countries such as the United States and Australia use untreated greywater for agriculture and gardening. This serves as a medium for improving food and water security and ultimately, alleviating poverty (Faruqui and Al-Jayyousi 2002). Greywater can be treated on-site with small-scale domestic treatment technologies (Bagget et al., 2006). Greywater management is mostly the responsibility of private individuals.

According to Nkonyeasya (2010), wastewater has been used in agriculture for centuries and is a low-cost alternative to conventional irrigation water. Scott et al. (2004) find that the use of wastewater in agriculture supports livelihoods and provides value despite associated environmental risks.

Ogidiaka (2006) finds that nutrient recovery for agriculture allows water conservation, provides a low-cost method for disposal of wastewater, and reduction of polluted rivers. Olomukoro and Egborge (2003) on the other hand find that the use of wastewater in agriculture has negative health risks for irrigators and communities with prolonged contact with treated wastewater, as well as the consumers of vegetables irrigated with wastewater. Arimoro et al. (2007) suggest that these can be managed by regular treatment of farmers and families with anthelmintic drugs. Idris-Nda et al. (2013) suggest the reuse of wastewater be adopted as a disaster risk reduction strategy for urbanised areas in developing countries like Nigeria. 


\subsection{Decentralised and Integrated Water-Energy-Nutrient Reclamation System}

There are numerous limitations encountered with the use of centralised water systems (Domenech, 2011). These limitations led to the implementation of decentralised systems in developed countries, enabling the enhancement of water security and environmental degradation in these countries (Domenech 2011). Sustainable alternatives suggested by Domenech (2011) include rainwater harvesting and greywater reuse at the household level.

According to Onabolu (2011), decentralised wastewater systems make use of on-site systems. Adogu et al. (2015) adds that though the decentralised system has its share of challenges. Authors identify some of these challenges (Adeyemo and Gboyesola 2013; Idu 2015; Onabolu et al. 2011) include the lack of a proper design concept, improper maintenance of the system, inappropriate technology, and improper siting of infrastructure. For these reasons, authors (Akin-Oriola 2003; Arimoro and Osakwe 2008; Kadiri 2006; Ogidiaka 2006) suggest the use of an integrated wastewater system in Nigeria to also aid in energy and nutrient recovery from wastewater.

Water supply in delta state is through boreholes, and submersible pumps, overhead/ground tanks, and wastewater collection and treatment is through ventilated improved toilet (VIP), septic tanks, Imhoff tanks which are connected to soil wastewater infiltration systems which in most cases are soakaway pits. According to Osirike (2003), individual homes in delta state are not connected to the piped Water. Decentralisation relies on the supply of piped Water using hydraulic paradigms (Kallis and Coccossis, 2003).

A decentralised system would require the collection of wastewater at the end-of-pipe in treatment plants for treatment. These include blackwater, greywater, brown-water or faecal matter, and yellower (Langergraber and Muellegger 2005). These are returned to the receiving water bodies together with valuable nutrients that become lost in the process once treated. It is the duty of the government, therefore to build infrastructure such as sewage systems, desalination plants, dams, and water transfers, in order to reclaim and reuse Water (Bakker 2002). Domenech (2011) compares the centralised and decentralised wastewater management as presented in Table 2.

Table 2: Comparison of centralised and decentralise water system (Source: Domenech, 2011)

\begin{tabular}{|c|c|c|}
\hline Factor & Centralised water management & Decentralised water management \\
\hline Scale & Large scale systems. & Small scale systems (domestic). \\
\hline Type of water sources & Distant and local water sources. & Local water sources. \\
\hline Governance & Top-down governance model. & Multi-level governance model. \\
\hline Ownership & $\begin{array}{l}\text { Water supply and sanitation infrastructure is } \\
\text { owned by the public sector. }\end{array}$ & $\begin{array}{l}\text { Water supply and sanitation systems } \\
\text { are owned by private individuals. }\end{array}$ \\
\hline $\begin{array}{l}\text { Control of the water } \\
\text { cycle (power) }\end{array}$ & $\begin{array}{l}\text { Controlled by the public sector and/or private } \\
\text { companies. }\end{array}$ & Controlled by private individuals. \\
\hline Participation & $\begin{array}{l}\text { Very limited public participation in water } \\
\text { management. }\end{array}$ & $\begin{array}{l}\text { Active public participation in water } \\
\text { management. }\end{array}$ \\
\hline Awal & Citizens are alienated from the water cycle. & $\begin{array}{l}\text { Citizens become more aware of the } \\
\text { water cycle. }\end{array}$ \\
\hline Cost sharing & Highly subsidised. & Full cost recovery. \\
\hline Water quality & Very high water quality for all uses. & $\begin{array}{l}\text { Different water qualities and fit-for- } \\
\text { purpose water use. }\end{array}$ \\
\hline Health risks & Health risl & $\begin{array}{l}\text { Risk management by the individuals } \\
\text { is required. }\end{array}$ \\
\hline $\begin{array}{l}\text { Environmental } \\
\text { impacts }\end{array}$ & Environmental impacts are significant. & Environmental impacts are reduced. \\
\hline Social conflicts & $\begin{array}{l}\text { Dam construction and water transfers usually } \\
\text { give rise to social conflicts between regions. }\end{array}$ & Social conflicts are less likely. \\
\hline Resilience capacity & $\begin{array}{l}\text { Limited adaptation capacity to extreme } \\
\text { situations. }\end{array}$ & $\begin{array}{l}\text { Enhanced capacity of adaptation to } \\
\text { different situations. }\end{array}$ \\
\hline
\end{tabular}

\subsection{Strategy requirements for implementing sustainable water \& wastewater systems}

In order to adopt decentralised technologies, it is necessary for governments to develop policies and new governance arrangements, as was done in Barcelona (Swyngedouw 2005). It might also be required to apply some incentives for adoption, especially for the oil and gas companies. Compared to the centralised system, the decentralised system will require the involvement of private individuals, communities, families, and neighbourhood associations (Swyngedouw 2005). Authors (Eynard et al. 2000; Owuli 2003; Omenka 2010) suggest a combination of technologies that promote reuse of wastewater.

The water supply scheme developed in Nigeria country is barely functional for several reasons including lack of skilled manpower, frequent leakages from the pipes which is worn in many places due to age and material used in construction, inconsistent power supply, financial issues, and poor management. In Delta state and Nigeria at large, Omenka (2010) finds that wastewater treatment facilities are privately owned by landlords, 
and are constructed together with the houses, and approved by the lands and surveys ministry for newer buildings. Furthermore, there is no ministry presently in charge of routine checks to ensure adequate functionality and health safety of these facilities managed by private landlords such as repair of breakages and leakage, or the dislodging of the sludge when the septic tank is full or overflowing.

Omenka (2010), therefore suggests a system, of which management will include accountability, coordination, and proactive monitoring of the system. Romans and Arabs used traditional systems in the Iberian Peninsula to collect, store, and reuse rainwater (Gutiérrez-Ayuso 2001). Recycling rooftop rainwater and greywater are leads to more efficient use of available Water. These are locally generated and can be reused onsite with the installation of relatively simple technologies. Some areas have higher rainfall than others (Pandey et al. 2003). The risks facing the implementation of decentralised systems include public health concern; concern of loss of revenue by water supply agencies, cost concerns, maintenance requirements Krozer et al. (2010) Roy et al., 2008. It is the duty of policymakers to facilitate a successful transition towards sustainable water management by adopting transition management strategies (Rotmans et al., 2001).

\section{Methodology}

\subsection{Research Method}

Interpretivism was adopted for this study because the research philosophy seeks to find meanings based on the belief that elements of a study should be interpreted and integrated with human interests in the study. The research philosophy also adopted a subjective ontology and subjective epistemology. Meaning is created from the study because human beings are involved in evaluating the development of water/wastewater reclamation (treatment and purification) processes and technologies, particularly water reclamation from oil and gas activities. An inductive research approach is then applied.

A mixed-method is adopted for this investigation; and is based on the use of qualitative data from interviews and secondary data, and quantitative data from questionnaire survey. A qualitative approach is selected in this research to emphasise non-statistical and non-numerical analysis of the research data collected through a case study approach and other secondary data sources such as existing information from related sources. The qualitative data also involves a detailed survey of literature in investigating the treatment of Wastewater in Delta State and proffer a better alternative approach. The search enables evaluating wastewater treatment in Delta state to ascertain the sustainability of the current techniques used by the Delta State Ministry of Water Resources and the influence of oil and gas activities. The study required subjective and objective data, allowing the collection of data from employees working at the ministry of water resources, wastewater management organisations, and oil and gas organisations in delta state. This data consisted of their personal opinions with a detailed explanation which could only be obtained effectively using qualitative methods. This is because qualitative method gives room for understanding aspects of social life by collecting such data.

A cross-sectional horizon of the State of wastewater management in Delta state Nigeria was used in the study. This method involves the use of data collected at the same point in time, and not considering the difference in time. The other method that could have been used is the longitudinal time horizon. However, it was not found suitable for the study. This was because it has been seen in literature that the State of Water and water management over time in Nigeria has been basically the same. Furthermore, the previous State of wastewater management in Nigeria is not useful at this point, rather, the information needed is the current State of wastewater management in the country, and the current impact of oil and gas activities. From this description, it can be deduced that the longitudinal horizon involves the collection of data over a period, which usually is many years

\subsection{Sample}

The study adopted the convenience sampling technique. As the name implies, the method allows the collection of a sample for a survey-based convenience and the factors surrounding the collection. Convenience sampling was also used because the interviewees were key informants who were willing to share their opinions. This technique enabled the sample size to be determined based on factors influencing the study, such as time, financial resources, and geographical constraint. The sample consisted of 15 employees conveniently selected from the ministry of water resources, Oil and Gas Company, and a wastewater management company in Delta State, Nigeria. These employees have working experience of 2 years to 20 years in these organisations. The study did not involve managers since it was not conducted at the organisational level.

\subsection{Data Collection}

Data was collected primarily through semi-structured interviews and closed-ended questionnaires on wastewater treatment and management in Delta State, which can be found in the next section. A sample of senior and junior non-management staff of the ministry of water resources, and oil and Gas Company, and a wastewater management company in Delta State were asked questions that focus on how wastewater is treated and reused. 
Both questionnaires and interviews were used to collect data in the study because as mentioned earlier, they enable meaningful data collection from a small sample size, allowing participants to relay their experiences and opinions on the subject matter.

Semi-structured interviews were used because they allow for flexibility and organisation while collecting data, contrary to structured interviews which have to predetermine questions making the process rigid, and unstructured interviews without predetermined disorganised which could be disorderly. The interviews were conducted over the phone, and each interview lasted for a maximum of 1 hour. Telephone interviews were used because of geographical constraints. However, this method did not affect the data collected, as it could have been the same as those collected in person. Secondary data were also obtained from Journal articles, books, and other reliable online sources and reports, to compare to the methods of wastewater management in Delta State.

\subsection{Interview and Questionnaire Design}

The purpose of the interviews and the questionnaires was to solve the water-wastewater (Pollution \& flooding), energy \& nutrient problem in domestic/community level and Oil \& gas industry level. The target audience, therefore, was the oil \& gas companies, and water \& wastewater companies, who also serve as the local planning / operational authority. The questions were in three phases, based on the framework developed within this study, and are listed below.

1. What type of water distribution system is used in Delta state?

2. What are the challenges faced in water management in the Delta state?

3. What are the challenges faced by wastewater industries in Delta state?

4. What are the strategies employed to ensure sustainable water management in the Delta state?

5. Describe the State of technology used for wastewater treatment in Delta state?

6. How technologies and methods can be improved to reduce over-reliance on the fresh/potable water use (water reclamation, recycling \& reuse)?

7. What can Sustainable alternative approaches are employed in the treatment and disposal of wastewater/ local runoff in Delta State?

8. How do oil and gas activities affect water supply in Delta state?

9. What are the standards, regulations, policies and legislation in place regarding wastewater reclamation and reuse from oil and gas activities in-house or on-site level in Delta state?

10. How can a decision support system (DSS) or strategy/planning framework be developed for selecting sustainable alternative for water/wastewater treatment and management in oil \& gas industries in Delta state?

The questionnaires were distributed to individuals working in the Oil and Gas industry, water management, and wastewater management companies. The interviews were conducted to gain in-depth information. Fifteen interviews were conducted, and 15 questionnaires were also distributed.

\subsection{Method of Analysis}

Considering the nature of data collected was qualitative and quantitative, both qualitative and quantitative methods were applied in analysing the interviews and questionnaires, respectively. For this study, however, thematic analysis was used in analysing the interviews. The thematic analysis involved the identification of similar themes in data collected, and the development of logical evaluations. This method was applied in this study because it enabled identifying patterns in the interviews, leading to the description of phenomena relating to the research questions. The method was applied by transcribing the interview results, coding them, and identifying themes from the data.

The questionnaire data collected were analysed quantitatively using descriptive analysis in this research. The process of analysing the data quantitatively was in three phases: In the first phase, data collected through questionnaires were cleaned to remove noisy data that are not relevant. In the second phase, the data were transformed into a form that can be processed statistically. The final phase involves knowledge of discovery. Tables, graphs and other diagrams were used for explaining the result obtained.

3.5.1 Developing the Strategy Framework for Water-Wastewater Treatment in Delta State to Find a Sustainable Alternative for Oil, Gas, Water and Wastewater Industries and Authorities

The first step is the problem formulation, involving understanding the decision to be made, and identifying the sources pathways and receptors. The second level is the risk assessment, and it involved estimating the probability in terms of high, medium or low, estimating the consequences as well, estimating risk in terms of probability and consequences, and evaluating the risk by priority. The third step is the options appraisal, and it involved evaluating options available, assessing cost-effectiveness, social acceptance, and technology and management, and lastly selecting the preferred option. 


\section{Risk assessment}

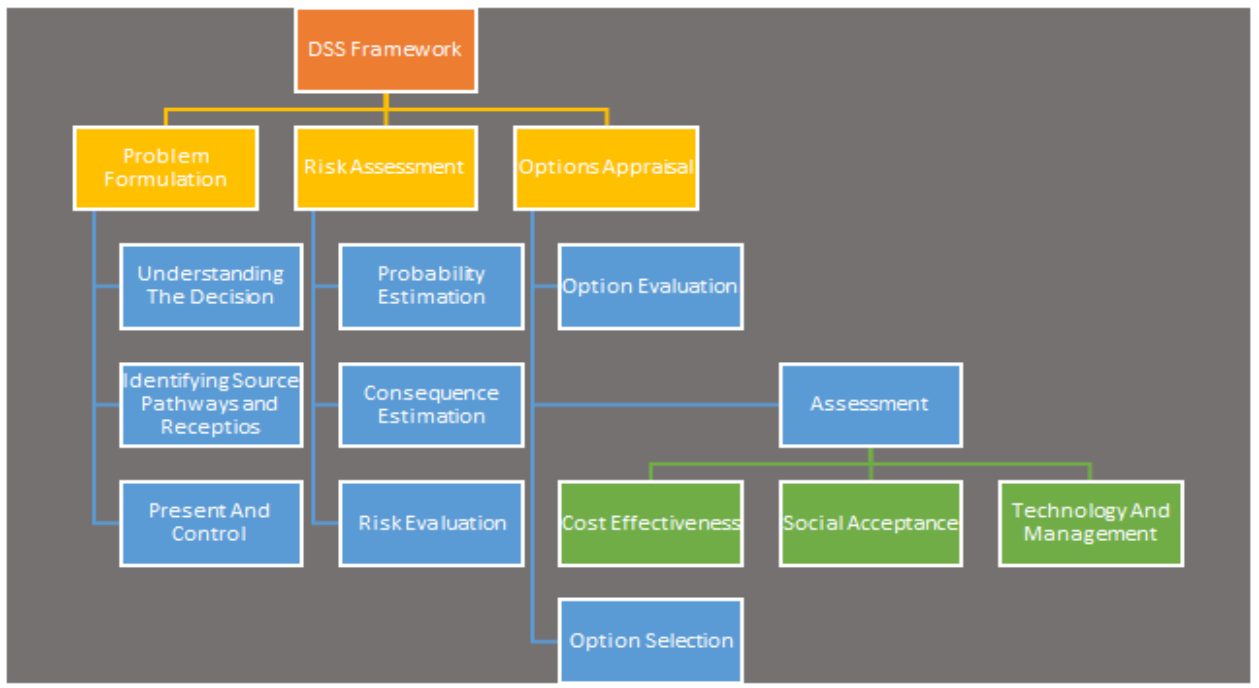

Figure 1: Plan for DSS Framework Development (Source: Authors)

The risk assessment in the decision support framework in the discussion section of this study will be based on the processes in Figure 2. Based on the risks to be identified in the data analysis section, the risk assessment will be modified for the conditions found in Delta State.

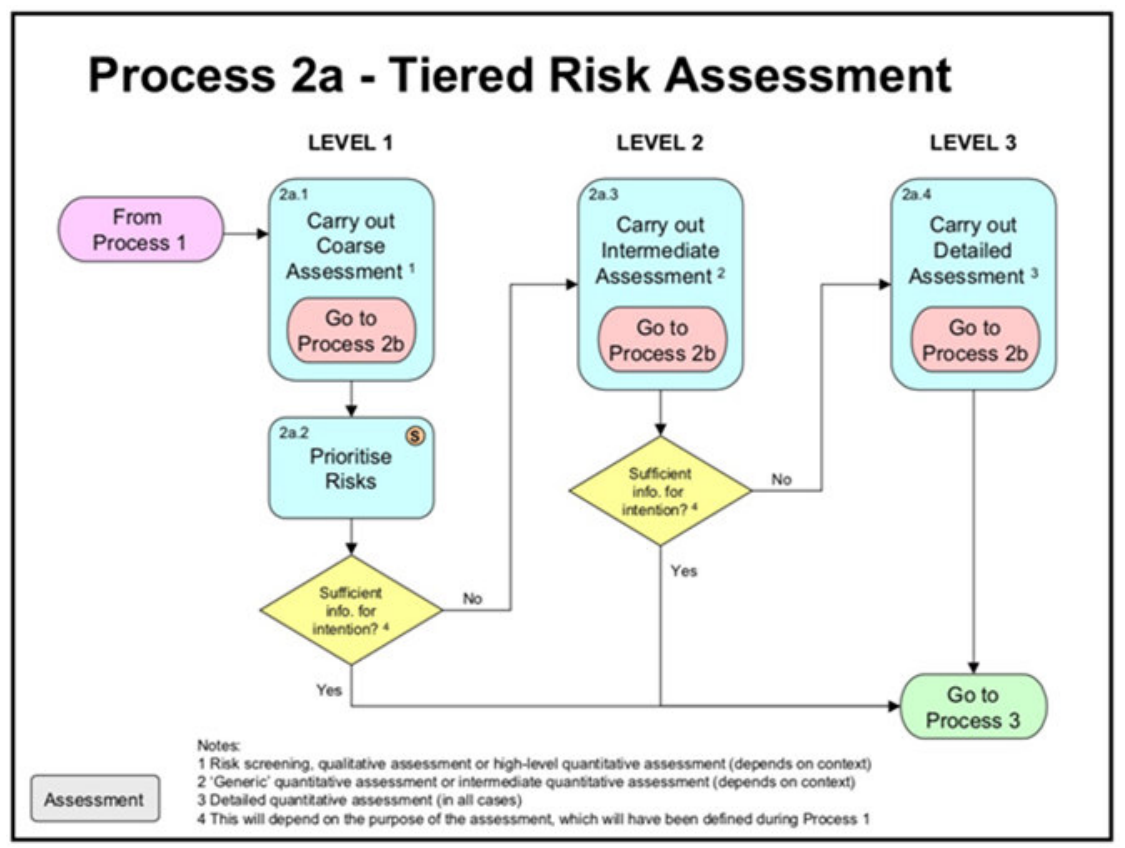

Figure 2: Process within the risk assessment

\section{Data Analysis and Discussion}

\subsection{Research Method}

The respondents were asked questions to provide knowledge on the nature of the water and wastewater problems in the State. The responses are shown in Tables and Charts.

\section{Water}

The respondents were asked if they think there is a water problem in Delta State. As shown in the Table 3, all the respondents agreed to this.

Table 3: Water problem (Source: Authors generated)

Do you think there is a water problem in Delta State?

No 
The respondents were asked to indicate top 5 causes that make identified water problems worse presently in Delta state by priority, for each of the problems listed in the Table 4 . The causing factor with the highest rank was high population, influencing each of the issues. The least cause was the use of potable Water for non-potable use. However, all the cases were found to be relevant.

Table 4: Present causes of problems (Source: Authors generated)

\section{Causes}

Using potable Water for non-potable use

Technical method not good enough for decreasing leakage of Water

Not enough land for development

Government regulation

Problems

Recent high population

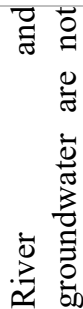

Maintenance not serious

People water awareness

Financial problem

Pollution

Water shortage
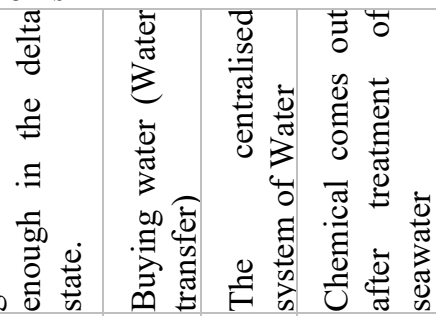

\begin{tabular}{c|c|c|}
\hline$\%$ & $\%$ & $\%$ \\
\hline 4 & 4 & 4 \\
\hline
\end{tabular}

\section{$\%$}

\begin{tabular}{|c|c}
\hline 0 & $\%$ \\
\hline 4 & 5 \\
\hline
\end{tabular}

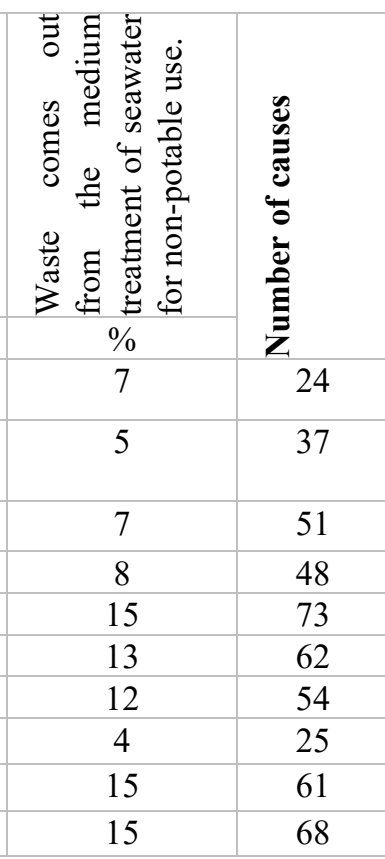

The respondents were asked to indicate top 5 causes that can make each of the problems worse in future in Delta state by priority. For each of the problems listed in Table 5. The causing factor with the highest rank was peoples' awareness on Water, highly influencing each of the problems. The least cause considered as climate change. However, all the cases were found to be relevant.

Table 5: Future causes (Source: Authors generated)

\begin{tabular}{|c|c|c|c|c|c|c|}
\hline \multirow[b]{3}{*}{ Causes } & \multicolumn{5}{|c|}{ Problems } & \multirow{3}{*}{ 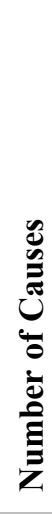 } \\
\hline & 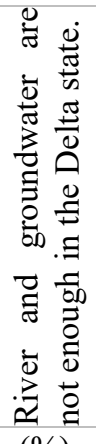 & 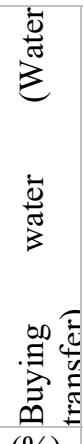 & 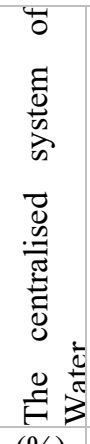 & 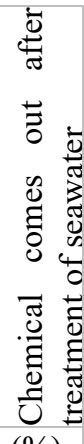 & 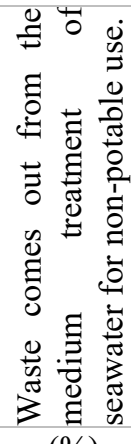 & \\
\hline & $(\%)$ & $(\%)$ & $(\%)$ & $(\%)$ & $(\%)$ & \\
\hline Using potable water for flushing & 5 & 3 & 7 & 4 & 5 & 24 \\
\hline Recent high population & 8 & 4 & 5 & 11 & 4 & 32 \\
\hline Maintenance not serious & 13 & 5 & 12 & 4 & 5 & 39 \\
\hline Technical method not good enough for decreasing leakage of water & 13 & 9 & 11 & 8 & 7 & 48 \\
\hline Not enough land for development & 11 & 8 & 9 & 7 & 8 & 43 \\
\hline People water awareness & 15 & 13 & 12 & 13 & 13 & 66 \\
\hline Government regulation & 11 & 13 & 11 & 12 & 12 & 59 \\
\hline Financial problem & 7 & 12 & 7 & 11 & 12 & 49 \\
\hline Climate challenge & 5 & 4 & 3 & 3 & 4 & 19 \\
\hline Socio-economic challenge & 4 & 13 & 13 & 13 & 15 & 58 \\
\hline Pollution & 8 & 15 & 11 & 15 & 15 & 64 \\
\hline
\end{tabular}


The respondents were asked why the water problems were important to them. From the Table 6 below, the major reason was that the problems affected their daily lives, and the least problem was because Water is not enough for productivity. However, all of the issues were found to be relevant.

Table 6: Reason for Problem (Source: Authors generated)

\begin{tabular}{|c|c|c|c|c|c|c|}
\hline \multirow[b]{2}{*}{ Causes } & \multicolumn{5}{|c|}{ Problems } & \multirow[b]{2}{*}{ 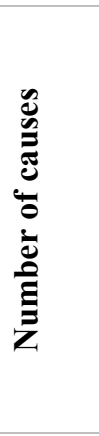 } \\
\hline & 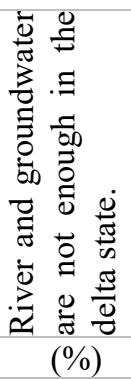 & 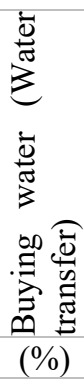 & 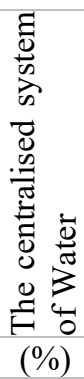 & 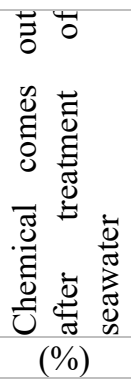 & 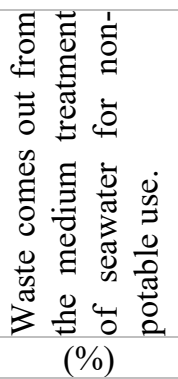 & \\
\hline Water is not enough for productivity & 13 & 7 & 13 & 13 & 13 & 59 \\
\hline Oil and Gas companies & 13 & 13 & 27 & 7 & 7 & 67 \\
\hline Increase the water buying price & 27 & 20 & 7 & 7 & 7 & 68 \\
\hline Health risk & 20 & 27 & 27 & 33 & 33 & 140 \\
\hline Affect daily life & 27 & 33 & 27 & 40 & 40 & 167 \\
\hline
\end{tabular}

The respondents were asked why the water problems were important to them. From the Table 6 below, the major reason was that the problems affected their daily lives, and the least problem was because Water is not enough for productivity. However, all of the issues were found to be relevant.

Table 6: Reason for Problem (Source: Authors generated)

\begin{tabular}{|c|c|c|c|c|c|c|}
\hline \multirow[b]{2}{*}{ Causes } & \multicolumn{5}{|c|}{ Problems } & \multirow[b]{2}{*}{ 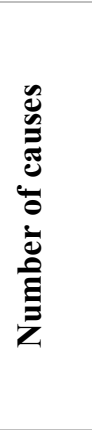 } \\
\hline & 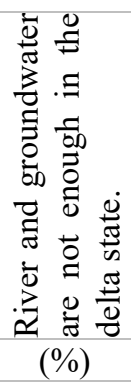 & 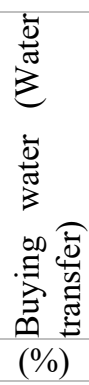 & 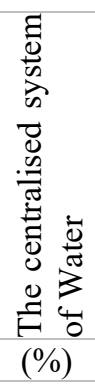 & 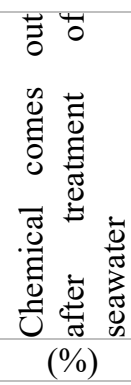 & 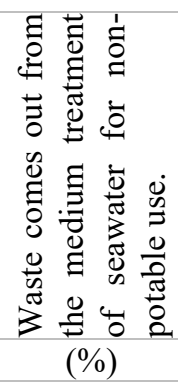 & \\
\hline Water is not enough for productivity & 13 & 7 & 13 & 13 & 13 & 59 \\
\hline Oil and Gas companies & 13 & 13 & 27 & 7 & 7 & 67 \\
\hline Increase the water buying price & 27 & 20 & 7 & 7 & 7 & 68 \\
\hline Health risk & 20 & 27 & 27 & 33 & 33 & 140 \\
\hline Affect daily life & 27 & 33 & 27 & 40 & 40 & 167 \\
\hline
\end{tabular}

\section{Wastewater}

The respondents were asked if they think there is a wastewater problem in Delta State. As shown in Table 7, all the respondents agreed to this.

Table 7: Wastewater (Source: Authors generated)

Do you think wastewater is a problem in a new development?

\begin{tabular}{|c|c|}
\hline & $(\%)$ \\
\hline Yes & 100 \\
\hline No & - \\
\hline
\end{tabular}

The respondents were asked to indicate top 5 causes that make each of the wastewater problems worse presently in Delta state by priority, for each of the problems listed in Table 8 . The causing factor with the highest rank was high population, influencing each of the problems. The least cause was financial. However, all the cases were found to be relevant. 
Table 8: Present causes of wastewater problems (Source: Authors generated)

\begin{tabular}{|c|c|c|c|c|c|c|}
\hline \multirow[b]{3}{*}{ Causes } & \multicolumn{5}{|c|}{ Problems } & \multirow{3}{*}{ 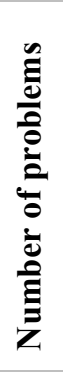 } \\
\hline & 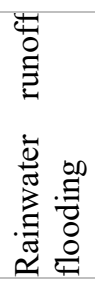 & 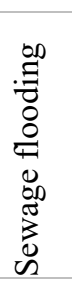 & 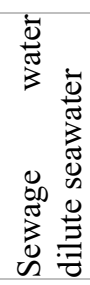 & 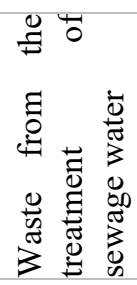 & 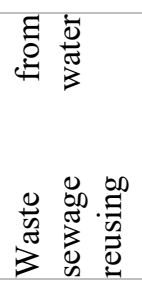 & \\
\hline & $\%$ & $\%$ & $\%$ & $\%$ & $\%$ & \\
\hline Using potable Water for non-potable use & 5 & 3 & 8 & 5 & 7 & 28 \\
\hline $\begin{array}{l}\text { Technical method not good enough for } \\
\text { decreasing leakage of Water }\end{array}$ & 8 & 4 & 7 & 12 & 5 & 36 \\
\hline Not enough land for development & 13 & 4 & 13 & 5 & 7 & 42 \\
\hline Government regulation & 13 & 11 & 12 & 7 & 8 & 51 \\
\hline Recent high population & 15 & 16 & 13 & 15 & 15 & 74 \\
\hline Maintenance not serious & 12 & 15 & 12 & 13 & 13 & 65 \\
\hline People water awareness & 9 & 13 & 7 & 12 & 12 & 53 \\
\hline Financial problem & 7 & 5 & 4 & 3 & 4 & 23 \\
\hline Pollution & 5 & 13 & 13 & 13 & 15 & 59 \\
\hline Water shortage & 12 & 16 & 11 & 15 & 15 & 69 \\
\hline
\end{tabular}

The respondents were asked to indicate top 5 causes that can make each of the wastewater problems worse in future in Delta state by priority, for each of the problems listed in Table 9. The causing factor with the highest rank was people's awareness, influencing each of the issues. The least cause was climate change. However, all the cases were found to be relevant.

Table 9: Future causes of wastewater problem (Source: Authors generated)

\begin{tabular}{|c|c|c|c|c|c|c|}
\hline & \multicolumn{5}{|c|}{ Problems } & \multirow{3}{*}{ 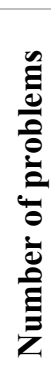 } \\
\hline & 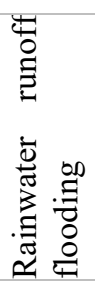 & 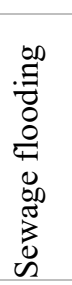 & 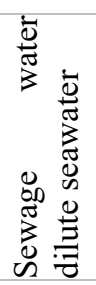 & 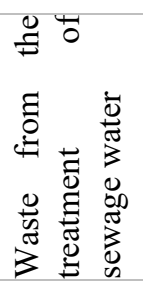 & 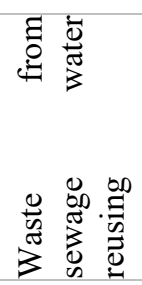 & \\
\hline & $(\%)$ & $(\%)$ & $(\%)$ & $(\%)$ & $(\%)$ & \\
\hline Using potable water for flushing & 5 & 3 & 7 & 4 & 5 & 24 \\
\hline Recent high population & 8 & 4 & 5 & 11 & 4 & 32 \\
\hline Maintenance not serious & 13 & 5 & 12 & 4 & 5 & 39 \\
\hline $\begin{array}{l}\text { Technical method not good enough for } \\
\text { decreasing leakage of water }\end{array}$ & 13 & 9 & 11 & 8 & 7 & 48 \\
\hline Not enough land for development & 11 & 8 & 9 & 7 & 8 & 43 \\
\hline People water awareness & 15 & 13 & 12 & 13 & 13 & 66 \\
\hline Government regulation & 11 & 13 & 11 & 12 & 12 & 59 \\
\hline Financial problem & 7 & 12 & 7 & 11 & 12 & 49 \\
\hline Climate challenge & 5 & 4 & 3 & 3 & 4 & 19 \\
\hline Socio-economic challenge & 4 & 13 & 13 & 13 & 15 & 58 \\
\hline Pollution & 8 & 15 & 11 & 15 & 15 & 64 \\
\hline
\end{tabular}

The respondents were asked why the wastewater problems were important to them. From Table 10, the major reason was that the problems affected their daily lives, and the least problem was because of the increasing prices of water. However, all the problems were found to be relevant. 
Table 10: Reason for the wastewater problem (Source: Authors generated)

\begin{tabular}{|c|c|c|c|c|c|c|}
\hline \multirow{3}{*}{ Causes } & \multicolumn{5}{|c|}{ Problems } & \multirow[b]{2}{*}{ 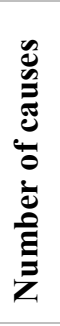 } \\
\hline & 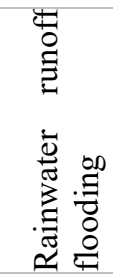 & $\begin{array}{l}\infty \\
: \Xi \\
0 \\
0 \\
0 \\
0 \\
0 \\
0 \\
0 \\
0 \\
0\end{array}$ & 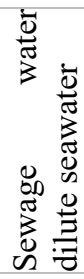 & 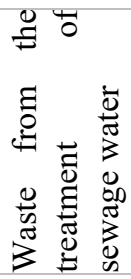 & 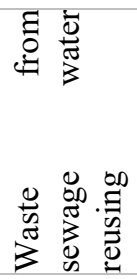 & \\
\hline & $\%$ & $\%$ & $\%$ & $\%$ & $\%$ & \\
\hline Water is not enough for productivity & - & - & 13 & 13 & 13 & 39 \\
\hline Oil and Gas companies & - & 7 & 27 & 7 & 7 & 41 \\
\hline Increase the water buying price & - & 13 & 7 & 7 & 7 & 21 \\
\hline Health risk & 47 & 33 & 27 & 33 & 33 & 93 \\
\hline Affect daily life & 53 & 47 & 27 & 40 & 40 & 107 \\
\hline
\end{tabular}

Figure 3 shows the collective results.

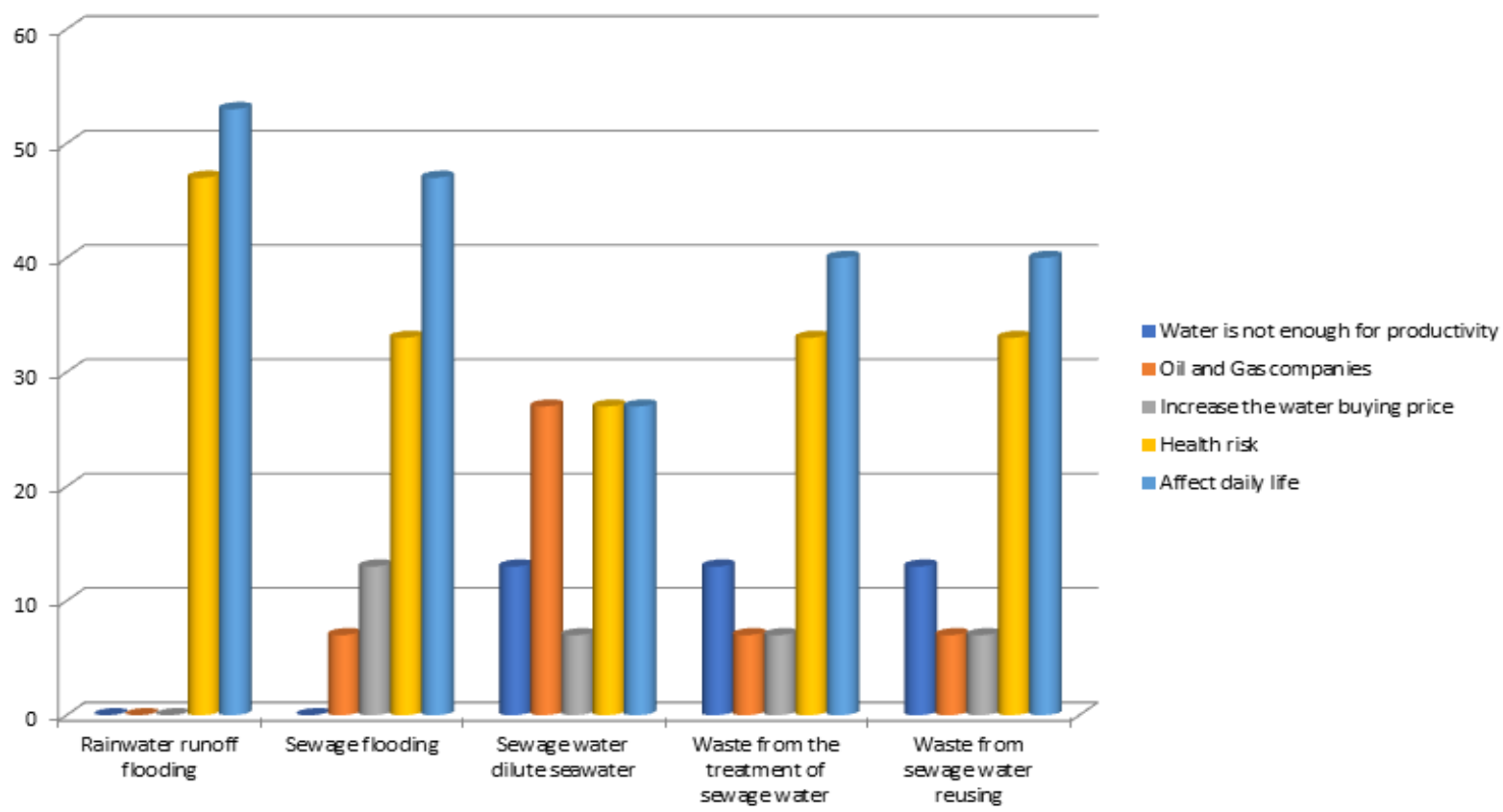

Figure 3: Reason for the wastewater problem (Source: Authors generated)

When asked to prioritize the water and wastewater problems, the problem with the highest-ranking was the use of a centralized system. The problem with the least ranking was waste from the treatment of sewage water reusing. The top four include a centralized system, rainwater runoff flooding, insufficient river and groundwater, and sewage problems. 
Table 11: Top 4 water and wastewater problem (Source: Authors generated)

\begin{tabular}{|l|c|}
\hline & $(\%)$ \\
\hline River and ground water is not enough for water demand in delta & 16 \\
\hline Buying water from retailers & 14 \\
\hline Centralised system & 21 \\
\hline Rainwater runoff flooding & 19 \\
\hline Sewage flooding & 14 \\
\hline Sewage water dilute seawater & 11 \\
\hline Waste from the treatment of sewage water reusing & 4 \\
\hline
\end{tabular}

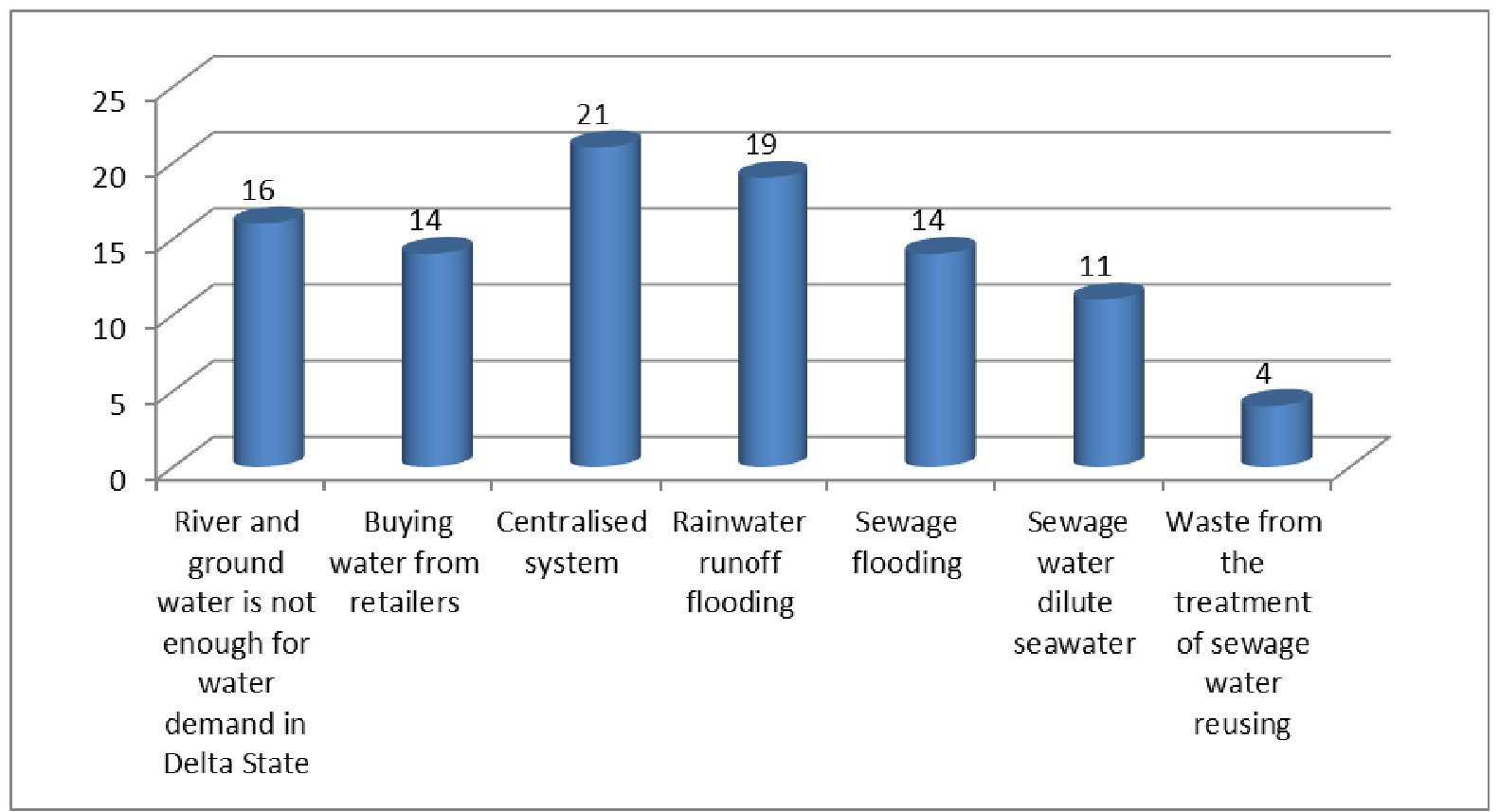

\section{Risk Assessment}

Figure 4: Top 4 water and wastewater problem (Source: Authors generated)

For this section, the questions were asked to determine the frequency and consequences of the risks posed by the wastewater management system in Delta state. As shown in Table 12, the problem with the highest frequency of occurrence was buying water from retailers, and the problem with the least probability of occurrence was waste from the treatment of sewage water reusing. All the other problems were found to at least a medium impact on the water and wastewater problems.

Table 12: Risk Assessment (Source: Authors generated)

\begin{tabular}{|l|c|c|c|c|c|}
\hline & & \multicolumn{3}{|c|}{ Occurrence of problem } \\
\hline $\begin{array}{l}\text { River and groundwater is not enough for water demand in } \\
\text { Delta }\end{array}$ & $\%$ & 9 & 82 & 9 \\
\hline Buying water from retailers & $\%$ & 10 & 10 & 80 \\
\hline Centralised system & $\%$ & 7 & 7 & 86 \\
\hline Rainwater runoff flooding & $\%$ & 15 & 62 & 23 \\
\hline Sewage flooding & $\%$ & - & 40 & 60 \\
\hline Sewage water dilute seawater & $\%$ & 13 & 25 & 62 \\
\hline Waste from the treatment of sewage water reusing & $\%$ & 100 & - & - \\
\hline
\end{tabular}




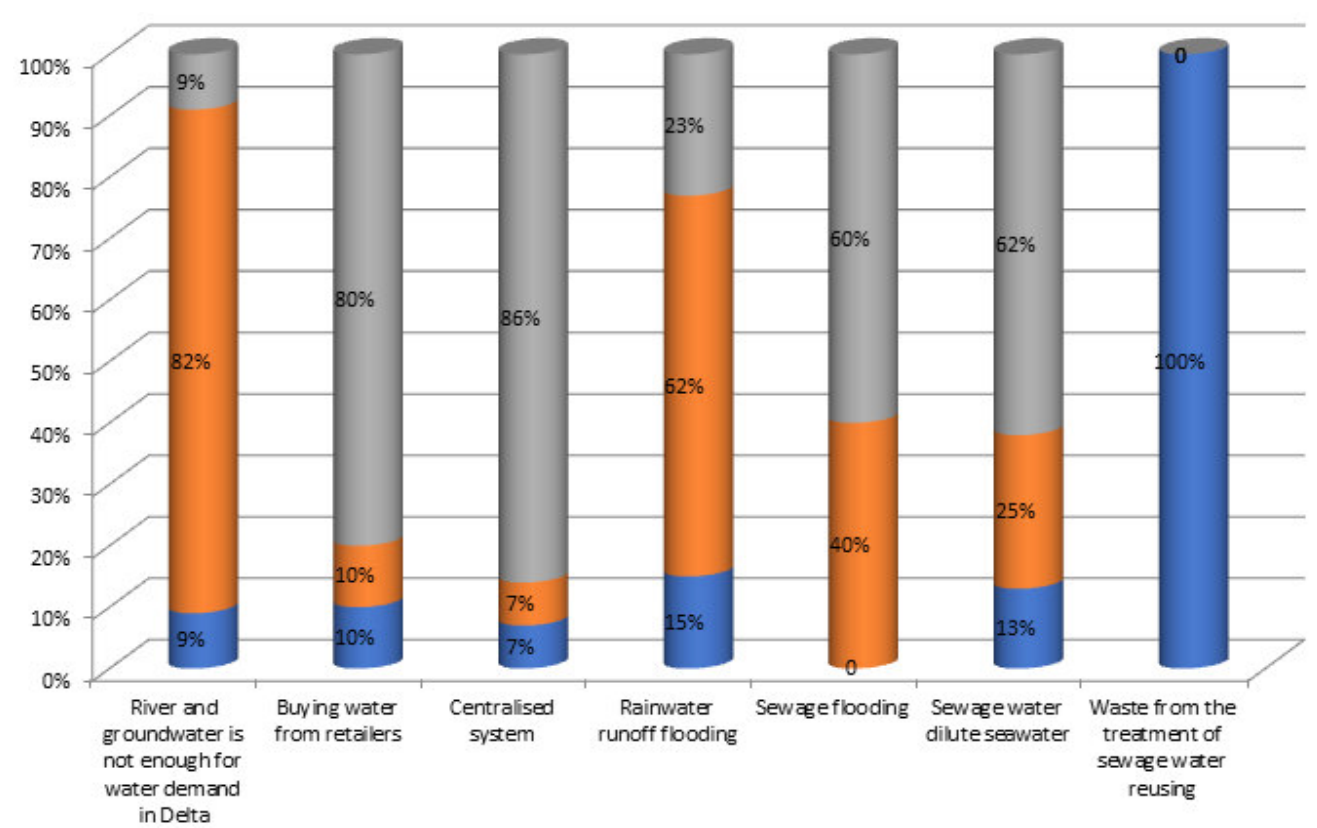

- High occurance

- Medium ocurance

- Low occurance

Figure 5: Risk Assessment (Source: Authors generated)

When comparing the severity of problems, waste from the treatment of sewage water reusing was found to be the problem with the highest severity, though it has the lowest probability of occurrence. The problem with the least severity was buying water from the retailers.

Table 13: Severity of risk (Source: Authors generated)

\begin{tabular}{|l|c|c|c|c|}
\hline & \multicolumn{3}{|c|}{ The severity of the problem } \\
\hline & & Low & Medium & High \\
\hline River and groundwater is not enough for water demand in Delta & $\%$ & 18 & 45 & 37 \\
\hline Buying water from retailers & $\%$ & 30 & 40 & 30 \\
\hline Centralised system & $\%$ & 20 & 33 & 47 \\
\hline Rainwater runoff flooding & $\%$ & 15 & 38 & 47 \\
\hline Sewage flooding & $\%$ & 10 & 30 & 60 \\
\hline Sewage water dilute seawater & $\%$ & 13 & 50 & 37 \\
\hline Waste from the treatment of sewage water reusing & $\%$ & - & 33 & 67 \\
\hline
\end{tabular}

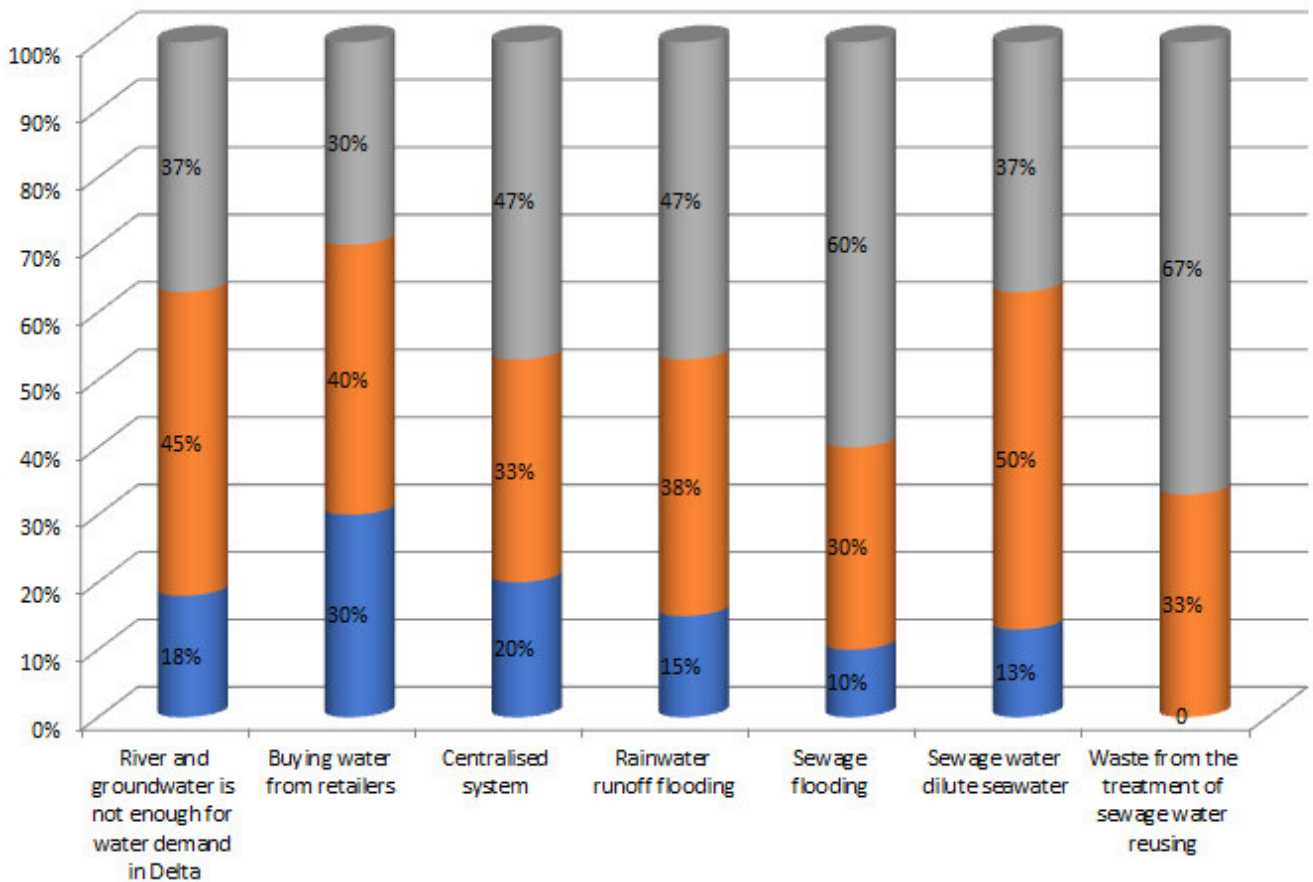

High occurance

Medium occurance

- Low occurance

Figure 6: Severity of risk (Source: Authors generated) 


\section{Suitable Alternatives}

A number of sustainable alternatives were assessed from the questionnaires. Table 14 shows the cost and economic effectiveness of the options. The option with the highest cost and economic effectiveness is the education and awareness of wastewater management. Other alternatives were also found to be either highly effective or medium.

Table 14: Cost-Effectiveness (Source: Authors generated)

\begin{tabular}{|c|c|c|c|c|}
\hline Sustainable alternatives cost-effectiveness. & & Low & Medium & High \\
\hline Existing wastewater system & $\%$ & 40 & 33 & 27 \\
\hline Better service by charging more & $\%$ & 27 & 33 & 40 \\
\hline Education and awareness of wastewater management & $\%$ & 20 & 33 & 47 \\
\hline Decentralised (in-house - onsite) reclamation of and reuse system & $\%$ & 33 & 33 & 34 \\
\hline
\end{tabular}

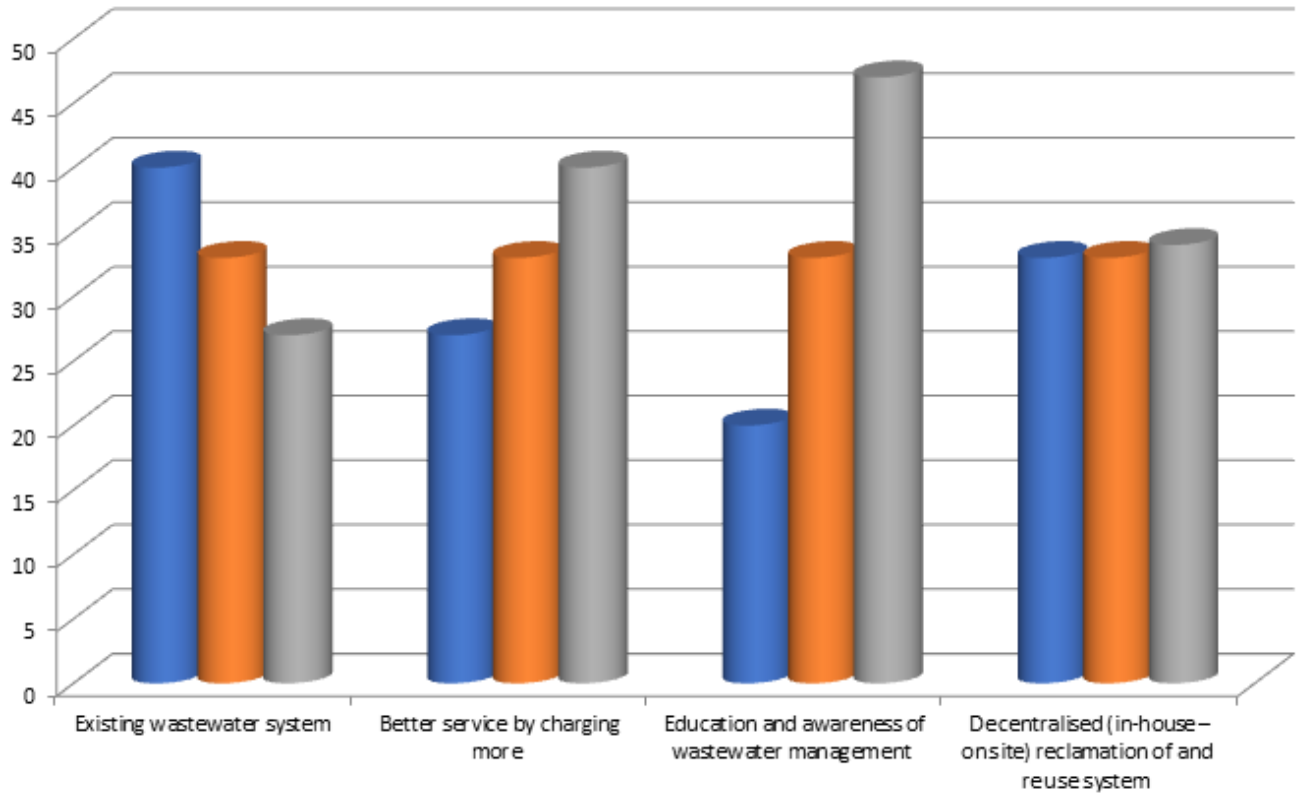

Figure 7: Cost-Effectiveness (Source: Authors generated)

The options were assessed for their social and regulations acceptability. Education and awareness of wastewater management and decentralized (in-house - onsite) reclamation of and reuse system were both found to be equally acceptable. Existing wastewater system and better service by charging more have less social acceptability.

Table 15: Social and regulations acceptability (Source: Authors generated)

\begin{tabular}{|l|c|c|c|c|}
\hline & & Low & Medium & High \\
\hline Existing wastewater system & $\%$ & 47 & 40 & 13 \\
\hline Better service by charging more & $\%$ & 40 & 47 & 13 \\
\hline Education and awareness of wastewater management & $\%$ & 13 & 33 & 54 \\
\hline Decentralised (in-house - onsite) reclamation of and reuse system & $\%$ & 7 & 40 & 53 \\
\hline
\end{tabular}




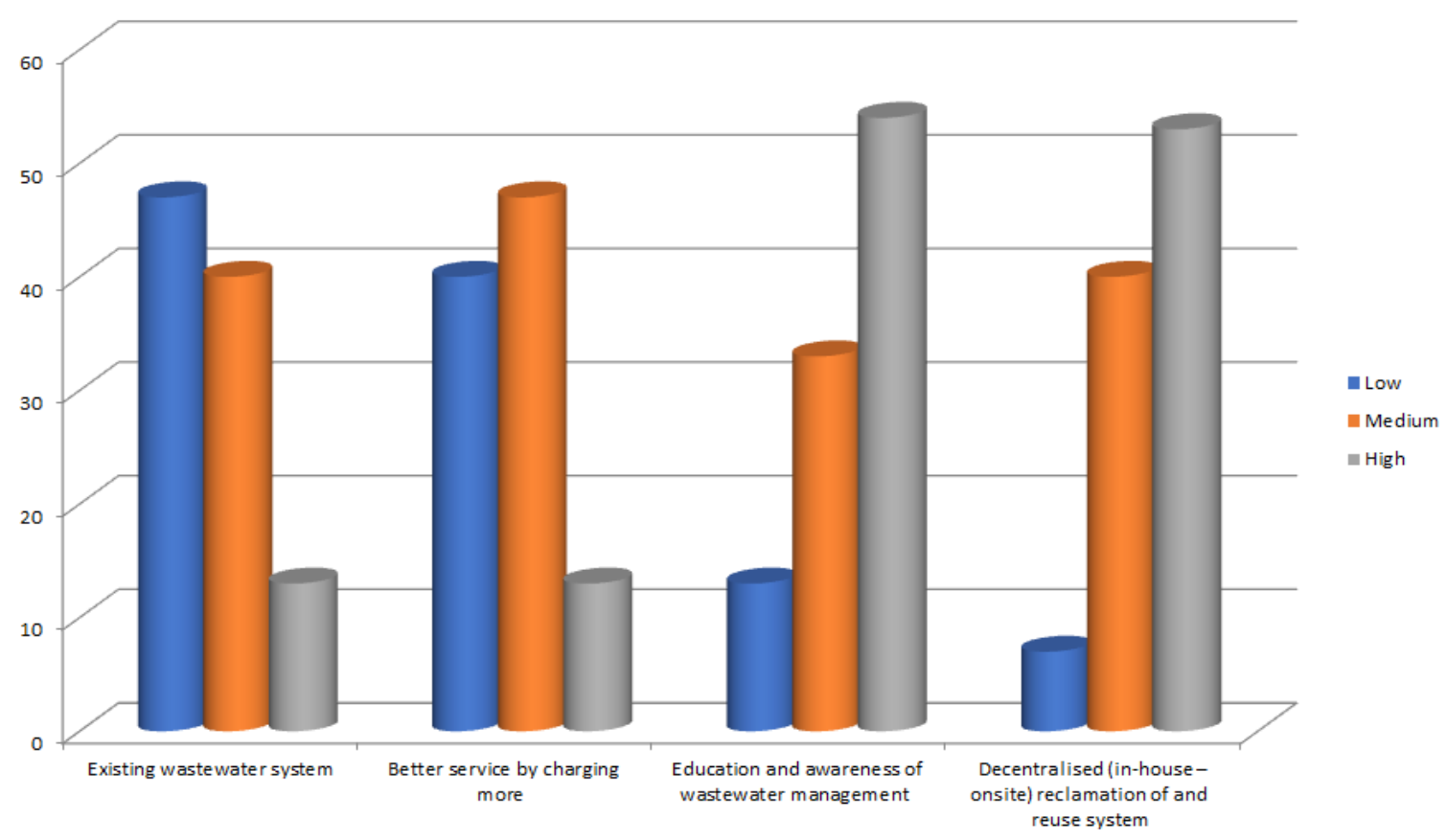

Figure 8: Social and regulations acceptability (Source: Authors generated)

The technical and management feasibility of the options were assessed. Education and awareness of wastewater management were found to have the highest rank.

Table 16: Technical and management feasibility (Source: Authors generated)

\begin{tabular}{|l|c|c|c|c|}
\hline & & Low & Medium & High \\
\hline Existing wastewater system & $\%$ & 53 & 33 & 14 \\
\hline Better service by charging more & $\%$ & 33 & 40 & 27 \\
\hline Education and awareness of wastewater management & $\%$ & 27 & 47 & 26 \\
\hline Decentralized (in-house - onsite) reclamation of and reuse system & $\%$ & 33 & 40 & 27 \\
\hline
\end{tabular}

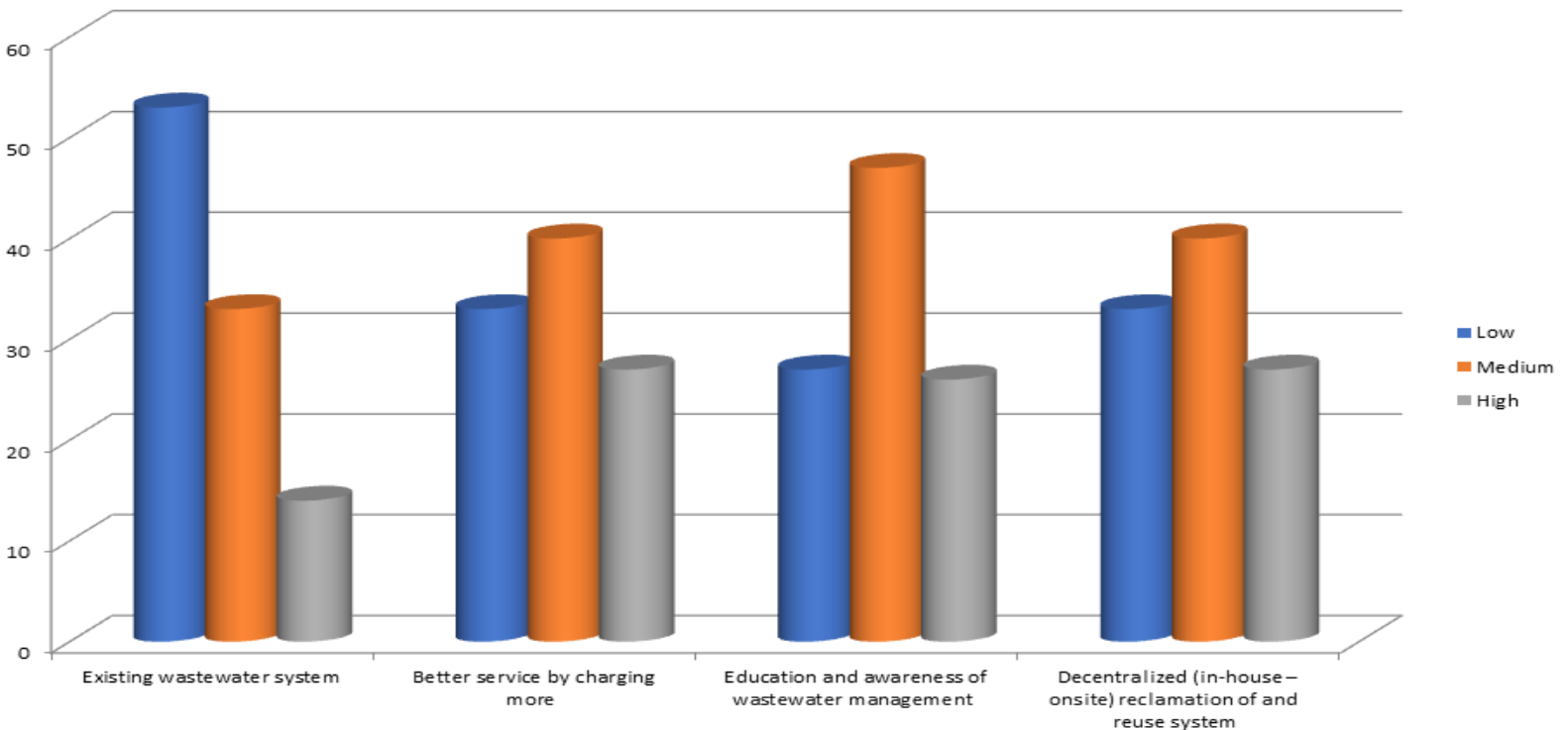

Figure 9: Technical and management feasibility (Source: Authors generated)

In assessing the environmental friendliness of the sustainable alternatives, education and awareness of wastewater management had the highest ranking. 
Table 17: Natural and built environmental friendliness (Source: Authors generated)

\begin{tabular}{|l|c|c|c|c|}
\hline & & Low & Medium & High \\
\hline Existing wastewater system & $\%$ & 47 & 33 & 20 \\
\hline Better service by charging more & $\%$ & 20 & 27 & 53 \\
\hline Education and awareness of wastewater management & $\%$ & 7 & 33 & 60 \\
\hline Decentralized (in-house - onsite) reclamation of and reuse system & $\%$ & 7 & 27 & 66 \\
\hline
\end{tabular}

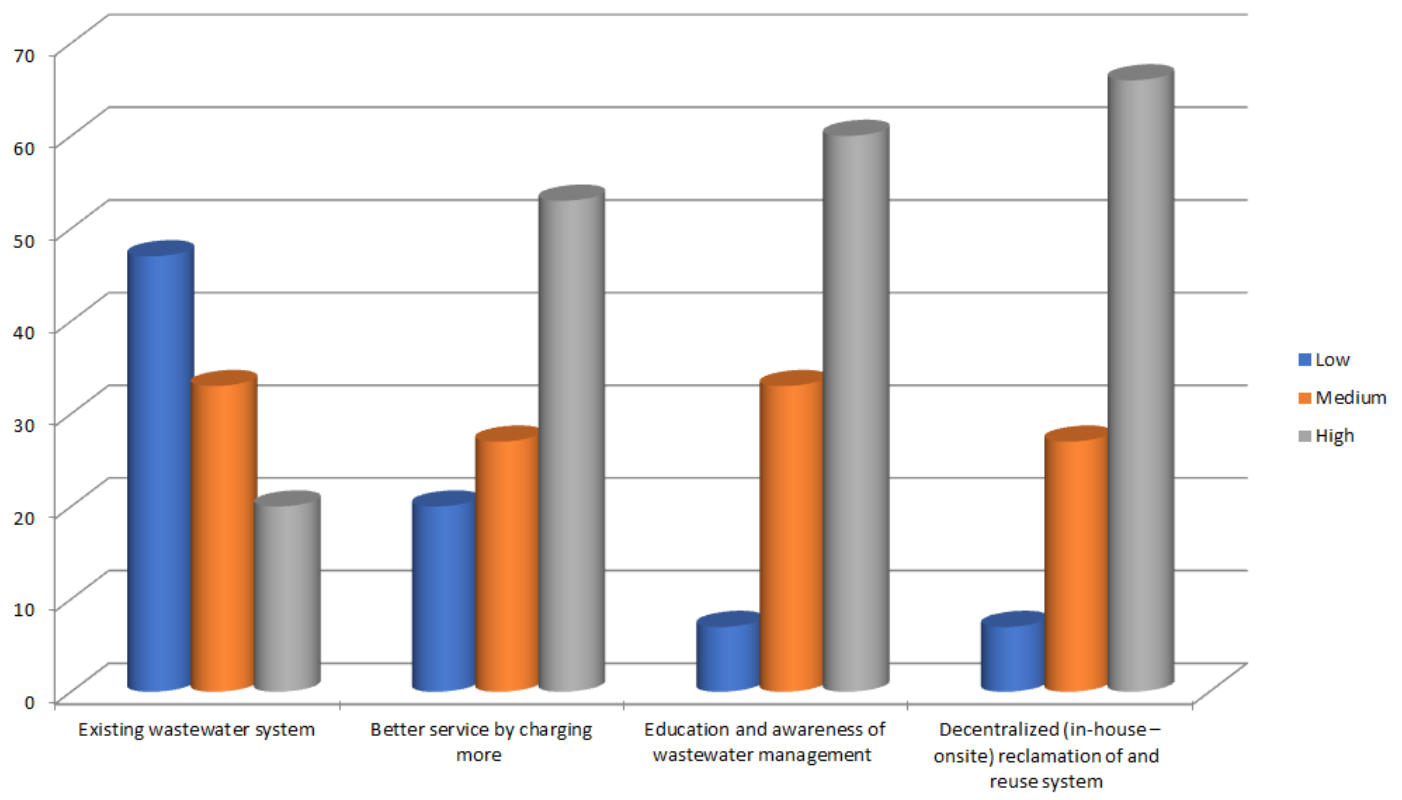

Figure 10: Natural and built environmental friendliness (Source: Authors generated)

When asked which option to be chosen for solving the problems, the respondents highly recommended the implementation of a decentralized system of water reclamation.

Table 18: Solutions (Source: Authors generated)

\begin{tabular}{|l|c|}
\hline & $(\%)$ \\
\hline Decentralised system of water reclamation & 60 \\
\hline Water treatment charging system & 7 \\
\hline Greywater reuse system & 33 \\
\hline
\end{tabular}

Based on the analysis of the sustainable alternatives, in terms of cost and economic effectiveness, social and regulations acceptability, education and awareness of wastewater management, and implementation of a decentralized (in-house - onsite) reclamation of and reuse system were found to be the best alternatives for Delta State.

\subsection{Interview Results}

To ensure the anonymity of the respondents, they are represented by codes when referred to in the analysis and discussion. Direct quotations from the interviewees are italicised.

How to improve and maintain quality of life through the sustainable supply water and dispose of wastewater including local runoff for all against a background of environmental, socio-economic and technological change

The type of water distribution system used in Delta state is centralized. This is characterized by the individual boreholes built by house owners, landlords, or estate owners. According to INTWR5, most of the house-owners in both semi-urban, and rural areas in Delta state need to build their own boreholes for water supply. This is because unlike some of the better developed states, most houses or buildings are unable to have water connected to them. Worse still, INTWR2 adds that the house owners in the rural areas mostly lack the funds required to construct boreholes, and have to depend on water from the streams, wells, and individually owned tanks. According to the interviewees, some of the residents have to buy water, especially drinking water from local vendors. Therefore, all the interviewees agreed that the water system in Delta state is centralized.

Wastewater management in Delta state is privately run. According to INTWWM4, several private organizations in the state are paid by the residents when they are needed to collect waste from their soakaway systems. This is the system usually used in urban areas. In rural areas, the residents sometimes dispose of waste 
personally, especially because they do not have sewage systems (INTOG1). The respondents believed the residents use domestic method to treat their water sourced from the boreholes, streams, rain, and wells. The residents also use the services of private wastewater disposal companies to clear out their soakaway. However, considering the system is not decentralized, there is no method of decentralized water distribution, rainwater collection, wastewater reclamation, wastewater reuse (INTWR1).

To improve and maintain quality of life through the sustainable supply water, the respondents believed there need to be drainage systems from which rainwater from roofs can pass to a central river, from which water can pass to individual buildings. This would be safer because the water would be treated by government standards which would be expected to be safer. However, the interviewees believed this is far-fetched because the state and country, in general, lack the finance and infrastructure to decentralize and treat water in the state. Considering the aspect of water reuse, the interviewees believed obtaining social acceptance on water treatment for domestic reuse will prove difficult. This is because the majority of the public would be unwilling to drink water they know was once in their toilets or waste disposal systems.

How to adapt current industrial \& domestic processes and practices to reduce over-reliance on the fresh/potable water use (water reclamation, recycling $\&$ reuse)

The interviewees believed there is no system in place to ensure recycling and reuse of wastewater in Delta state. According to INTOG1, currently, water reclamation in Delta state and Nigeria involves the removal of wastewater from soakaways. INTWR5 adds that most if not all of Delta state residents that have a disposal system make use of the soakaways. As previously described, the reclamation of waste requires the privatelyowned waste collection companies to clear the pits of the waste. According to INTWR3, this usually happens when the pit is filled up. At this point, the homeowners call the sewage management companies and pay for the service.

According to INTWWM4, the wastewater, however, is not treated for reuse. It is given off for farming and firefighting. This is because the organizations are unaware of the technologies for recycling wastewater, and do not see the viability of wastewater treatment for domestic reuse. However, it would be possible if the organizations invested in the technologies, to treat the individually collected wastewater for resale.

Based on these, wastewater collected by these companies is not intended for domestic reuse. Therefore, dependence on fresh and potable water use remains high in Delta state and Nigeria. When asked how the technology and methods can be improved in Delta state to reduce over-reliance on freshwater reuse, the interviewees believed, the sewage management companies need to improve their systems for wastewater collection and invest in technology for wastewater recycling. According to INTWR2, this way it would also be possible to collect rain and wastewater for treatment. When treated, this water can be sent back for domestic use. If this is implemented, the reliance on freshwater can be reduced.

Sustainable alternative approaches that can be employed in the treatment and disposal of wastewater/ local runoff in Delta State

Most of the non-oil-and-gas-interviewees were unaware of the methods used for water treatment on a large scale. The oil and gas interviewees mentioned that water is treated in the industry, and privately to the organizations using the trickling filter, and activated sludge process. All the oil and gas interviewees suggest that the activated sludge process be adopted if a decentralized system is developed.

How the wastewater should be treated (reclaim), recycled and reuse from oil and gas activities in-house or onsite level as a decentralized system in Delta State

All the interviewees agree that oil and gas activities in Delta state have a high level of impact on water supply in the state. According to INTWWM1, considering that some of the residents get their water for domestic use and farming from the rivers and streams, they are affected by oil and gas activities. INTOG5 adds that this is usually because of the oil spill, and is sometimes because of bunkering and vandalism by the residents themselves. However, according to INTWWM2, though the oil companies are required to treat their wastewater before releasing it back for use, it is possible that they do not treat it the best way they can. This is mostly because the government does not mount enough pressure on them to ensure the safety of the residents of Delta state (INTWR2).

When asked their opinion on the standards, regulations, policies and legislation in place regarding wastewater reclamation and reuse from oil and gas activities in-house or onsite level in Delta state, the interviewees responded that currently, there are regulations requiring the oil and gas companies to treat produced water before disposing of it in the rivers. However, the majority of the interviewees also add that there is the possibility that this is not done to book because they are not being monitored. According to INTWR5, it is also possible that the oil and gas companies also dump their waste in the streams as well.

How to develop a decision support system (DSS) or strategy/planning framework for selecting sustainable alternative for water/wastewater treatment and management in oil \& gas industries in Delta state

The interviewees believed a decision support system or strategy framework would require a system that integrates operations of oil and gas organizations, ministry of water resources, and to a large extent, sewage 
management companies.

According to INTWWM3, as is expected, it will also require a great deal of planning, financial, time, and human resource investment. Making the system decentralized would take a long time considering it is currently completely centralized. However, INTWWM4 adds that the process could start out small, by first ensuring water collected by the sewage companies is recycled and reused. At the next stage, the government should work towards improving the drainage and gutters to ensure rainwater is reclaimed. According to INTOG3, the government could work towards decentralization of major towns, taking them one at a time. When this begins, they would require a central plant where the wastewater can be treated using ASP, and the treated water can be a return to the streams and rivers. INTOG4 adds that the government could also ensure that the produced water from the oil and gas companies is properly treated according to regulation, and is linked to the decentralized system to be distributed to the residents' houses for reuse. According to INTWR4, the government should also continue making the wastewater available for reuse in agriculture and firefighting.

\subsection{Conclusion}

In this chapter, the data collected using questionnaires and interviews are analyzed. It was found that there is a water problem in Delta State, and wastewater is a problem in new development. Present and future water and wastewater problems include insufficient river and groundwater, water transfer, centralized water system, chemical come out after treatment of seawater, and waste comes out from medium treatment of seawater for non-potable use.

Present and future causes of water and wastewater problems include government regulation; financial problem lack of sufficient land for development; pollution; high population; using potable water for non-potable use; water shortage; poor technology; lack of water awareness of the people, and poor maintenance. The risk occurrence by rank is the use of centralized systems, purchase of water from retailers, sewage water mixing with seawater, sewage flooding, rainwater runoff flooding, and insufficient river and groundwater for demand.

Based on this, the decentralized system of water reclamation and education and awareness of wastewater management are sustainable alternatives for Delta state. Greywater reuse system was also found to be a sustainable alternative. The next chapter covers the discussion of the findings.

\section{DISCUSSION OF FINDINGS}

How to improve and maintain quality of life through the sustainable supply water and dispose of wastewater including local runoff for all against a background of environmental, socio-economic and technological change

It was found that the water management system in Delta state is centralized. Considering findings by Izonfuo et al. (2013), it was expected that since the sources of water are centralized, the disposal of wastewater is also centralized in this state. It was found that the centralized system consists of mostly individual boreholes, especially in urban areas, due to the lack of connected pipes to houses. More than half of rural areas in Nigeria do not have access to piped water, and the scenarios where it is available, Adekalu et al. (2002) find that it is irregular resulting from poor infrastructures and deterioration of the schemes available. Other sources include the streams, rivers, wells, and water purchased from local vendors. This is like findings by Badejo et al. (2006) who found that some individuals in Nigeria and many other African countries have to purchase water for daily use, invest in wells, storage tanks, and boreholes. According to Onabolu (2011), the household taps in the rural areas are not fully reticulated to the decentralized water supply systems, thereby creating a need for an integrated water quality monitoring system.

It was also found in the study that the residents' health and daily life are affected by challenges resulting from poor water and wastewater systems. According to Idris-Nda et al. (2013) and Komolafe et al. (2009), this is the expected impacted of contaminated water on individuals, affecting their health and daily lives. Though very few respondents opined that the challenges do not occur regularly. It is, however, possible that these respondents referred to the urban areas. Which was found by authors (Adegoroye 2008; Konate 2012; Onaruwa and Fakayode 2002; Tanimu et al. 2011) to have much fewer water challenges than the rural areas, as more of these parts have better water management that of the rural areas.

Furthermore, it was found in the study that challenges posed by oil and gas activities to the condition of water in the Delta state occurs regularly. According to authors (Bahadori 2014; Onojake 2012; Reynolds 2003; Veil et al. 2004), this is a usual problem faced in oil-producing countries and states. It was found that a sustainable source of water is from rainwater, which some of the residents personally collect, boil/filter, and store for reuse. Rainwater, however, was found to be the only sustainable alternative that might be considered by the respondents, as it was found that other forms of wastewater might not be acceptable by the users.

It was found that a centralized system to collect rainwater, and wastewater will be required to recycle water in Delta state for reuse and reduce dependence on freshwater. It will be an improvement to the direct collection of wastewater from individual houses by private waste management organizations that drain the sewage systems. 
It was found that the waste is already used for agriculture, and fire services, but not energy. However, the sector lacks workforce, infrastructure and finances to be more effective.

A system needs to be developed to collect wastewater in a central site for treatment and recycling. This would require better drainage systems, rooftop harvesting, fixing of piped networks, and other forms of rainwater extraction. The system needs to address social acceptance, fits the socio-cultural domain to welcome the changing water cultures, with no health risks (Head 2008). It will also be necessary to plan against financial burdens and redistribution (Coombes et al. 2002) because decentralized systems are more costly than centralized systems (Fane and Mitchell 2006) for a better system to be implemented.

How to adapt current industrial \& domestic processes and practices to reduce over-reliance on the fresh/potable water use (water reclamation, recycling $\&$ reuse)

On a collective basis, wastewater is not recycled for reuse in delta state. For this to be possible, the water sources and disposal methods in Delta state such as boreholes, submersible pumps, overhead/ground tanks, and treatment through ventilated improved toilet (VIP), septic tanks, Imhoff tanks which are connected to soil wastewater infiltration systems which in most cases are soakaway pits need to be modified. According to Osirike (2003), individual homes in Delta state are not connected to the piped water. Decentralization relies on the supply of piped water using hydraulic paradigms (Kallis and Coccossis, 2003).

Though wastewater is removed from the soakaways, it is not recycled for domestic reuse. To reduce reliance on freshwater, there is a need for water reclamation, recycling, and reuse. This can be done by adopting the decentralized system as suggested by numerous authors and would require the collection of wastewater at the end-of-pipe in treatment plants for treatment, including blackwater, greywater, brown water or faecal matter, and yellow water (Langergraber and Muellegger 2005). These are returned to the receiving water bodies together with valuable nutrients that become lost in the process once treated.

In addition, it will be necessary to follow Bakker (2002) suggestion to build infrastructures such as sewage systems, desalination plants, dams, and water transfers, to reclaim and reuse water, as it was found that most houses do not have proper disposal systems in delta state. Industrial processes will require onsite treatment, offsite treatment, and conventional treatment (Wang et al. 2013). The poor onsite systems such as pit latrines and septic tanks need to be improved. For onsite treatment, wastewater collected should be transported to sites for treatment (Mara and Alabaster 2008).

What sustainable alternative approaches can be employed in the treatment and disposal of wastewater/ local runoff in Delta State

Considering industrialized societies meet water demand with the supply of greywater, rainwater, stormwater, and wastewater (Gleick 2003), sustainable approaches that can be adopted in Delta State include recycling rooftop rainwater and treating greywater. These are locally generated and can be reused onsite with the installation of relatively simple technologies. Microscale solutions such as ponds, permeable pavements, rain gardens, rainwater harvesting systems, wetlands, and green roofs as identified by Brown (2005) can be adopted. According to UNEP (2009), rainwater harvesting includes storage in ponds and collection of water from the soil. Roy et al. (2008) however identify that the rainwater and harvesting and other sustainable approaches are affected by cost, insufficient engineering standards, inefficient guidelines, lack of legislative mandate, fragmented responsibilities, resistance to change, lack of institutional capacity, and lack of funding. As found in the study, the government needs to put in more effort in achieving this.

Considering the disposal of wastewater, agriculture is a useful and effective means. Wastewater, as found by Olaleye and Adediji (2005), is useful in agriculture. It was found that many industrialized countries such as the United States, and Australia use untreated greywater for agriculture and gardening. This serves as a medium for improving food and water security and ultimately, alleviating poverty (Faruqui and Al-Jayyousi 2002). Ogidiaka (2006) finds that nutrient recovery for agriculture allows water conservation, provides a low-cost method for disposal of wastewater, and reduction of polluted rivers.

How wastewater should be treated (reclaim), recycled and reuse from oil and gas activities, in-house, or onsite level as a decentralized system in Delta State

Oil and gas activities in Delta state have a high level of impact on water supply in the state and considering that some of the residents get their water for domestic use and farming from the rivers and streams, they are affected by oil and gas activities. It was found that though the oil companies are required to treat their wastewater before releasing it back for use, it is possible that they do not treat it the best way they can. This is mostly because the government does not mount enough pressure on them to ensure the safety of the residents of Delta state. Idu (2015) also finds that the industrial effluents are discharged into water directly, without prior treatment, or indirectly, and can increase water quality parameters. From the findings in the study, it is suggested that water a system be developed for treatment, which would require the companies to return the treated water back to the streams and sources, which is partly successful on the part of the oil and gas companies.

Oil and gas activities do pose numerous challenges to the state of water in Delta state. Authors who have conducted studies in oil-producing countries and states (Abu-Zeid 1998; Bahadori 2014; Reynolds 2003; Veil et 
al. 2004) find that this is a similar problem faced in these countries and states. Currently, in Nigeria, there are regulations requiring the oil and gas companies to treat produced water before disposing of it in the rivers. However, there is the possibility that this is not done to book because they are not being monitored. Similarly, Izonfuo et al. (2013) found that the Nigerian government has not done much in terms of wastewater management and monitoring oil and gas effects on water quality.

Similarly, Ekiye and Zeijao (2010) found that the major cause of water pollution in Nigeria, especially Delta, is industrial effluence, especially from oil and gas activities. It is suggested that the government needs to ensure these regulations are adhered to by the companies.

Considering inhouse and onsite treatment, the process requires planning and designing of facilities to determine the flow rates of wastewater, hydraulic design of sewers, the selection of sewer appurtenances and pumping stations, and large conduits and junction and diversion structures (Kaagu et al. 2013). After the treatment process, however,

How to develop a decision support system (DSS) or strategy/planning framework for selecting sustainable alternative for water/wastewater treatment and management in oil \& gas industries in Delta State

The water supply scheme developed in Nigeria country is barely functional for several reasons including lack of skilled manpower, frequent leakages from the pipes which is worn in many places due to age and material used in construction, inconsistent power supply, financial issues, and poor management in Delta State and Nigeria at large.

A decision support framework can be implemented, monitoring and integrating operations of oil and gas organizations, ministry of water resources, and to a large extent, sewage management companies. It is necessary to identify and plan for risks such as noted by (Krozer et al. 2010; Roy et al. 2008) including public health concern; concern of loss of revenue by water supply agencies, cost concerns, maintenance requirements. Punmia et al. (2007) add that wastewater management system should be assessed for risk in terms of cost criteria, cultural criteria, ecological criteria, health criteria, nuisance criteria, operational criteria, and reuse criteria.

It is the duty of policymakers to facilitate a successful transition towards sustainable water management by adopting transition management strategies (Rotmans et al. 2001). A regulatory body needs to be developed to monitor the system, as suggested by Omenka (2010).

\section{Conclusion}

From the discussion, it was seen that to maintain quality of life through the sustainable supply water and dispose wastewater including local runoff for all against a background of environmental, socio-economic and technological change; improvements need to be made to the systems of water and wastewater management in Nigeria. Methods such as rooftop harvesting, onsite treatments of wastewater, and disposal of wastewater by use in agriculture and energy can be adopted. The next chapter provides a summary and the strategic framework for transitioning to decentralized water systems.

\section{CONCLUSION AND RECOMMENDATIONS \\ 6.1 Conclusion}

The study was conducted in Delta state, Nigeria. The objectives were achieved by conducting a detailed review of literature, and collection of data using questionnaires and interviews. Developing water/wastewater reclamation (treatment and purification) processes and technologies particularly water reclamation from oil and gas activities in delta state is feasible. However, this implementation can only be done gradually. Oil and gas activities in Delta state have a high level of impact on water supply in the state and considering that some of the residents get their water for domestic use and farming from the rivers and streams, they are affected by oil and gas activities. Oil and gas activities pose numerous challenges to the state of water in Delta state.

Development of energy and nutrient recovery from water and wastewater treatment processes and technologies was also found to be feasible. Wastewater is currently used for agriculture and farming. However, a good strategic plan can guide the application in other areas, including energy recovery. Development of decentralized but integrated water-energy-nutrient reclamation (from oil and gas activities as decentralized treatment/recovery) system that help close cycles in ways to contribute to the environmental, social/health safety and economic benefits of the Delta was is also feasible. The centralized system in the delta state can be decentralized. A centralized system is required to collect rainwater, and wastewater, and recycle water in Delta state for reuse, and reduce dependence on freshwater. It will be an improvement to the direct collection of wastewater from individual houses by private waste management organizations that drain the sewage systems.

Sustainable approaches that can be adopted in Delta State include recycling rooftop rainwater and treating greywater. These are locally generated and can be reused onsite with the installation of relatively simple technologies. Micro-scale solutions such as ponds, permeable pavements, rain gardens, rainwater harvesting systems, wetlands, and green roofs as identified can be adopted. 


\subsection{Recommendations}

Based on the findings, sustainable approaches such as recycling rooftop rainwater, and treating greywater should be adopted. Micro-scale solutions such as ponds, permeable pavements, rain gardens, rainwater harvesting systems, wetlands, and green roofs as identified can be adopted. There is the need to ensure technology and infrastructure, such as pipes are built-in and maintained. The impact of inconsistent power supply, financial issues, and poor management need adequate attention.

The factors in planning for include public health, loss of revenue by water supply agencies, cost, maintenance requirements, cultural factors, ecological criteria, nuisance criteria, operational criteria, and reuse criteria. A regulatory body needs to be developed to monitor the system.

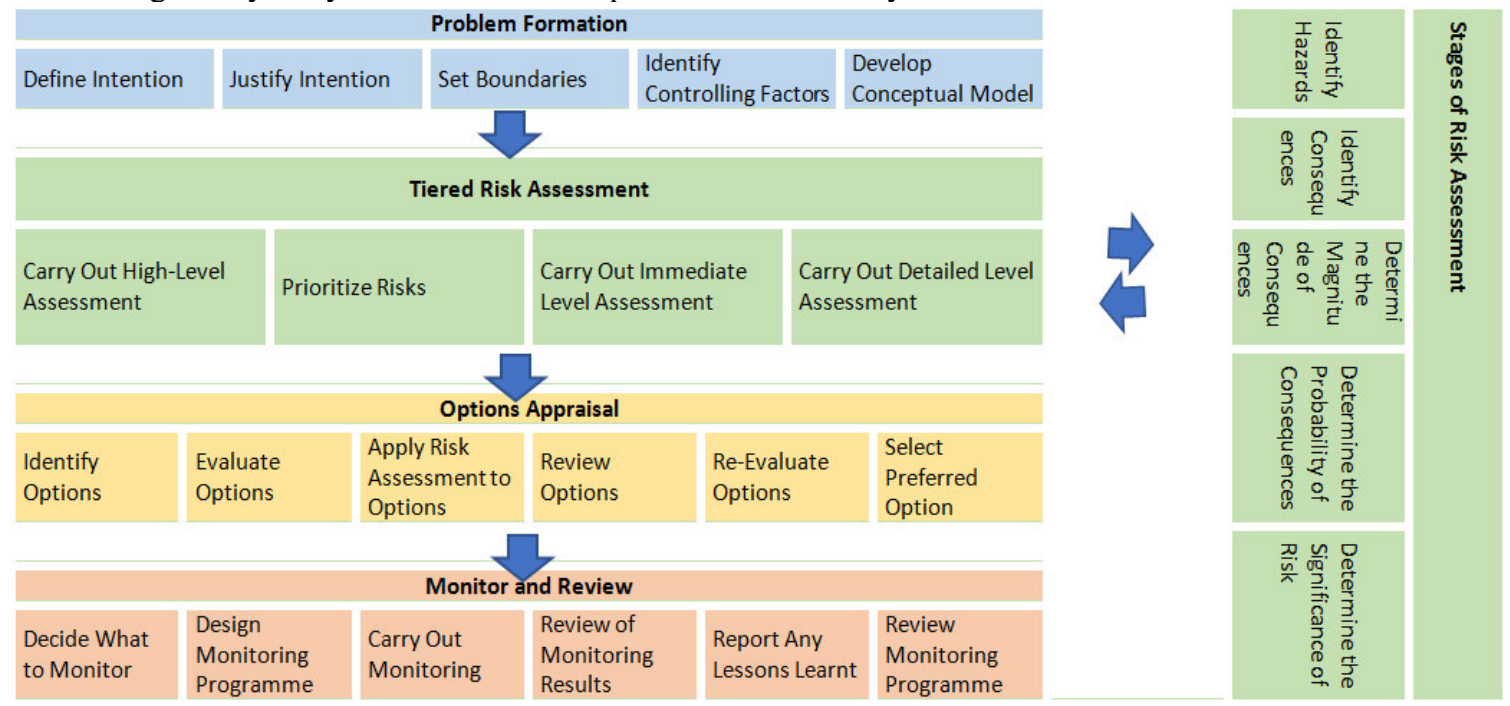

Figure 11: Strategic Framework/Decision Support System for Sustainable Alternatives for Oil, Gas, Water and Wastewater Industries and Authorities (Source: Authors)

From the study, the activated sludge process was suggested. The disposal can be done using methods such as land application, dilution in streams and rivers, and reuse in aquaculture and crop irrigation. Activated sludge treatment, combined trickling filter plants, and stabilization ponds would be effective for this purpose. The strategy framework to ensure all factors is properly considered when implementing a sustainable alternative in Figure 12.

As shown in Figure 11, the strategy/policy framework or DSS development for wastewater treatment is in 4 processes: Problem formulation; tiered risk assessment \& stages of risk assessment; options appraisal, and; implement the strategies, manage, monitor, review. These are discussed in detail over the next few sections.

The framework serves as a recommendation selecting sustainable alternatives for wastewater management in delta state as a sub-region in the south-south region of Nigeria. Considering similarities with other states in Nigeria, it is also recommended that relevant aspects be adopted or modified to suit the states in Nigeria.

\subsubsection{Problem Formulation}

In this step, the managing bodies must determine the purpose of the plan or project, which should be to select sustainable alternatives for wastewater management in the state. They should be able to define the problem clearly, to gain focus on the problem, and have appropriate output. This would enable the managers to make holistic decisions, which will result in value for money. The decision-making process needs to be transparent. The objectives should relate to ensuring the proper recycling of wastewater using an integrated approach. It should be noted that it would require a lot of time to achieve this, so little steps should be taken in time.

The problems can be addressed by using government regulations; improving finances, provision of sufficient land for development; water recycling for non-potable use; improved technology; improving water awareness of the people, and improved maintenance. The benefits would be an increase in water for productivity, proper management of oil and gas activities, managed health risks, improved daily lives, and managed water buying price.

\subsubsection{Tiered Risk assessment}

The second phase is the assessment of risk, as shown in Figure 12. This phase is highly linked to the stages of risk assessment in the next section. It requires the screening and prioritizing of risks to achieving objectives in the implementation of sustainable alternatives for wastewater management. This stage also requires carrying out intermediate assessments, then detailed assessments of the risk. This is important to ensure proportionate effort is applied in meeting decision-making requirements. As shown in Figure 11, assessments would also require a coarse assessment. To carry out the requirements of this phase, information is needed from the stages of risk assessment. Possible risks by severities include sewage flooding, the use of centralized systems, rainwater runoff 
flooding, insufficient river and groundwater for demand, purchase of water from retailers, and sewage water mixing with seawater.

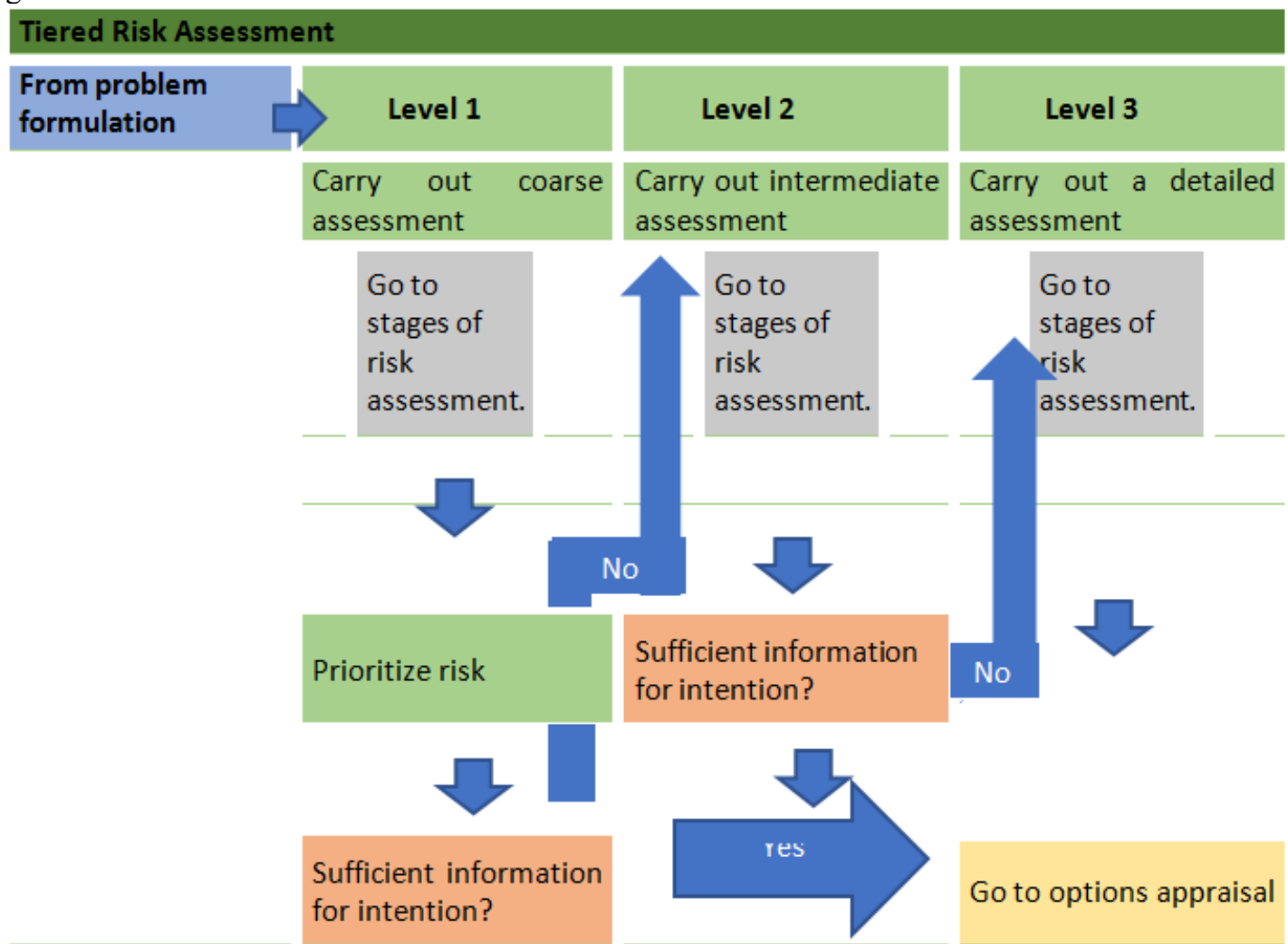

\subsubsection{Stages of risk assessment}

Figure 12: Tiered Risk Assessment (Source: Authors)

This phase requires the identification of hazards, and resulting consequences relating to the development of the decentralized wastewater system. The managers would be required to assess and determine the magnitude of the resulting consequences, as well as the probability of the consequences occurring. Most importantly, it will be necessary to determine the significance of the risks identified.

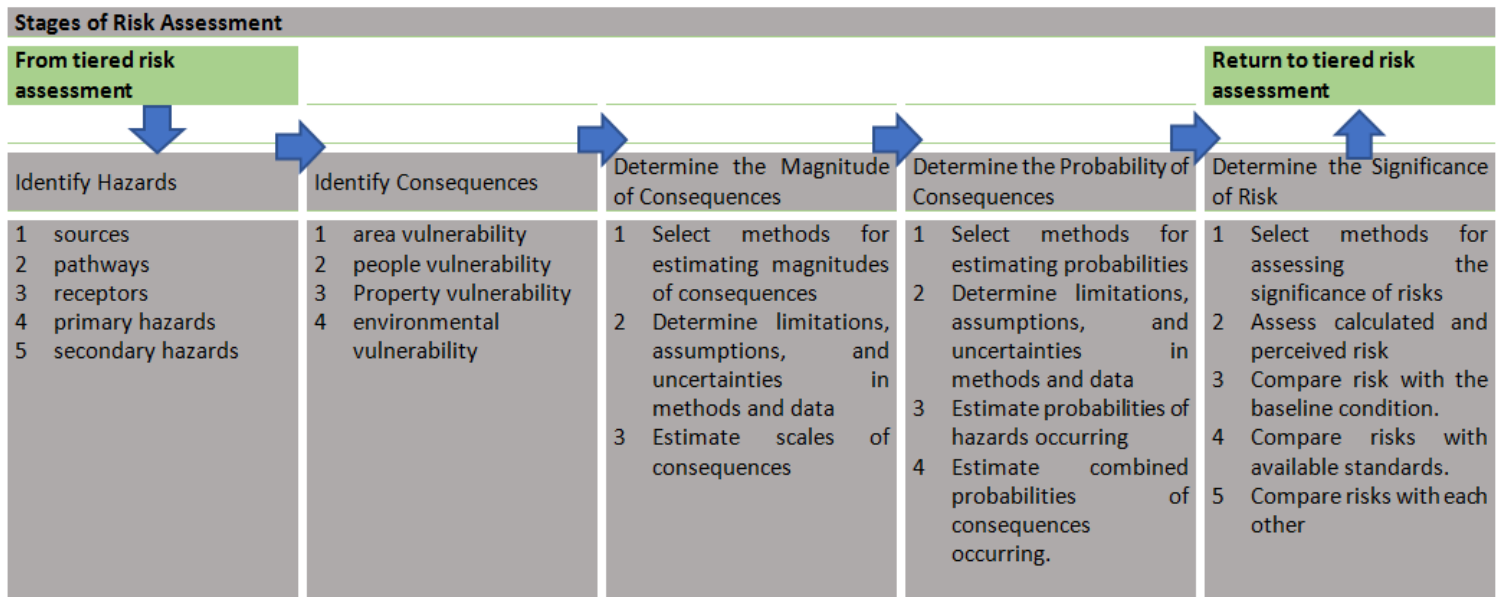

Figure 13: Stages of Risk Assessment (Source: Authors) 


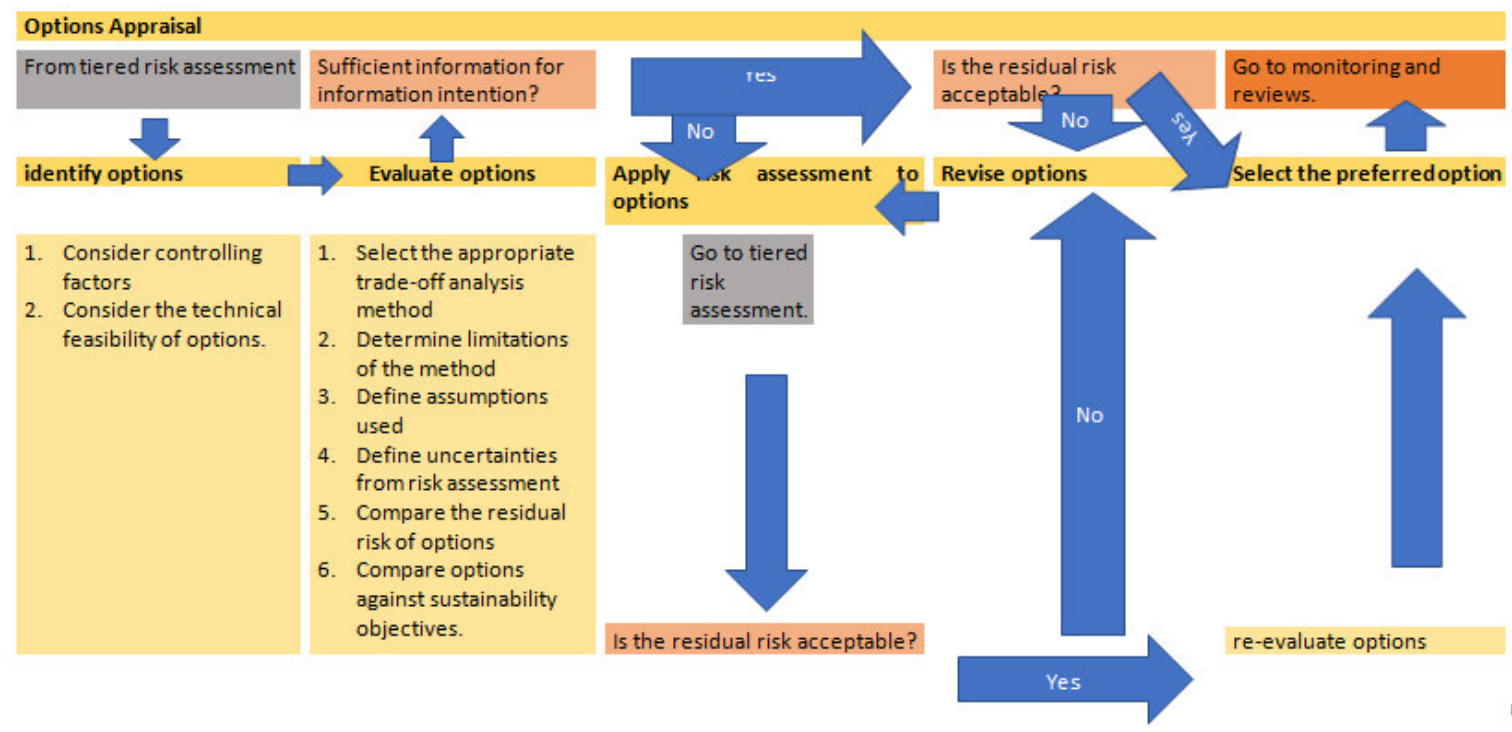

Figure 14: Options Appraisal (Source: Authors)

This phase requires the identification and evaluation of options for sustainable wastewater management. This should be based on social, environmental, economic, and technical feasibility. The options should have been assessed to with their risks; they should be revised, and then revaluated, after which an option should be selected.

Sustainable alternatives recommended include decentralized system of water reclamation, education and awareness of wastewater management, and greywater reuse system. They are cost-effective, socially and regulatorily acceptable, technically feasible, and environmentally friendly.

\subsubsection{Monitoring and Review}

The last phase requires monitoring and reviewing the selected method. This requires that the sustainable alternative has been chosen, and the system has been designed. The system will be monitored, and the results will be reviewed. Lessons learned would also be documented.

Implementation of the framework requires stakeholder engagement, including the public, to ensure their interests influence decision making. This is an essential part of sustainable development, allowing decision making based on shared knowledge and innovation. It is necessary to include the public, ministry of water resources, waste management organizations, and necessary state regulatory agencies in the process.

Homeowners should be required to ensure water is used efficiently and ensure their drainage systems work properly. Environmental agencies should also monitor the proper disposal of waste and wastewater, to ensure free flow in gutters and drainage system. The government can take steps to decentralize the system and adopt ASP in water treatment. It should also be enforced that the oil and gas companies follow certain standards in water treatment, and be monitored as well, for the safety of the residents.

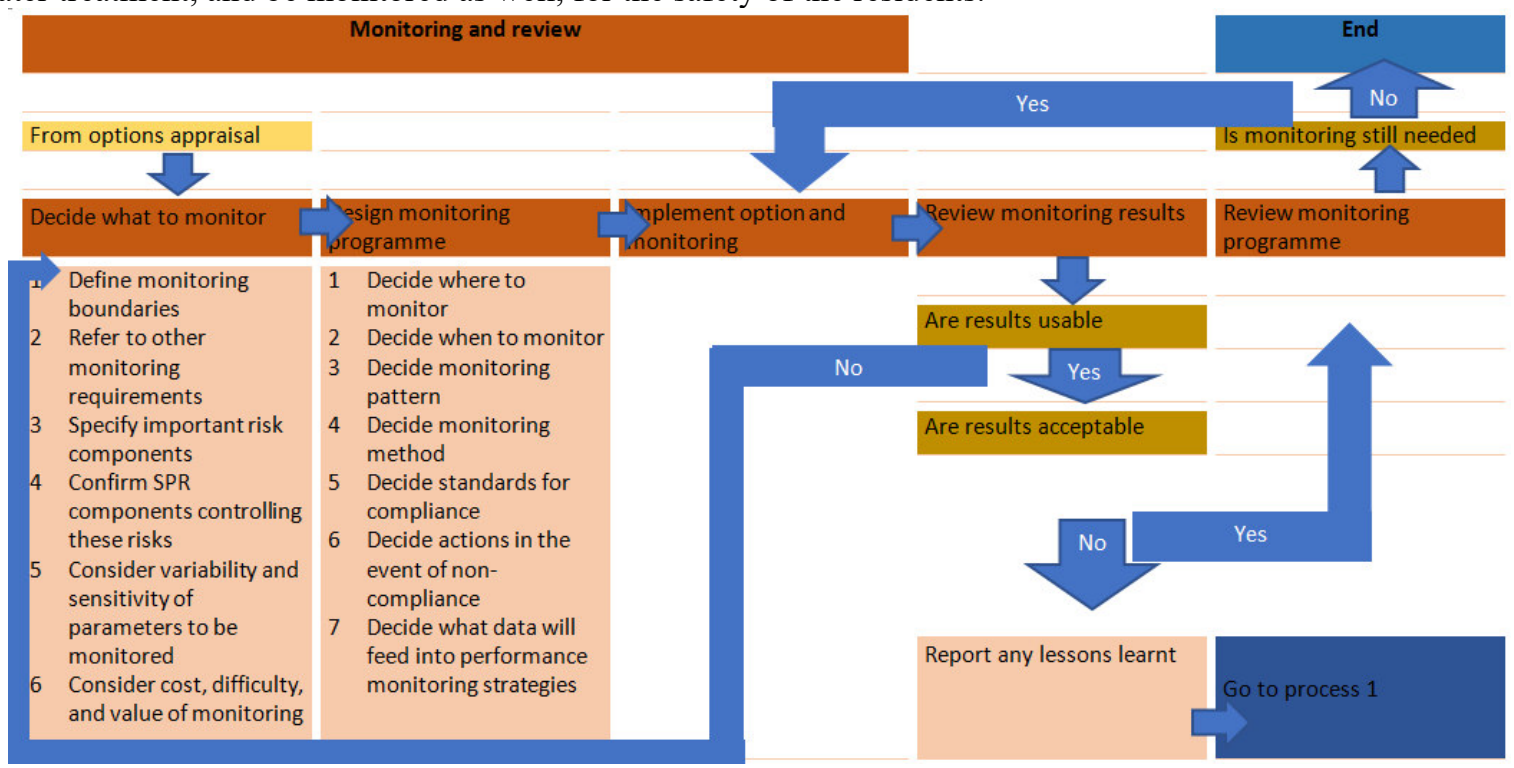

Figure 15: Monitor and Review (Source: Authors) 


\subsection{Recommendations for Further Study}

There are many opportunities for further studies in this research area, especially in Nigeria. Further studies can be done in other States of the country to determine sustainable alternatives, if different, especially in the non-oil producing states. Comparative studies can be done with other developing countries, to determine differences and similarities on social acceptance of wastewater reuse. Detailed studies can be conducted on the role of wastewater in energy and agriculture. Further studies can also be done adopting a longitudinal approach to determine the wastewater disposal methods adopted in Nigeria over time.

\section{References}

Absar, A.K. (2006) 'Water and Wastewater Properties and Characteristics', John Wiley and Sons, Inc., New Jersey.

Abu-Zeid, K. M. (1998) 'Recent Trends and Development: Reuse of Wastewater in Agriculture' Environmental Management and Health 9 (2), 78 -89

Adegoroye, A. (2008) 'The Challenges of Environmental Enforcement in Africa: The Nigerian Experience.' Proceedings of the Third International Conference of Environmental Enforcement, 43 - 52.

Adekalu, K. O., Osunbitan, J. A., and Ojo, O. E. (2002) 'Water sources and demand in south western Nigeria: Implications for water development planners and scientists.' Technovation 22 (12), 799-805. doi:10.1016/S0166-4972(01)00056-6.

Adeyemo, F.O. and Gboyesola, G.O. (2013) 'Knowledge, Attitude and Practices on Waste Management of People Living in the University Area of Ogbomoso, Nigeria.' International Journal of Environment Ecology, Family and Urban Studies, 3, 51-56.

Adogu, P.O.U., Uwakwe, K.A., Egenti, N.B., Okwuoha, A.P. and Nkwocha, I.B. (2015) 'Assessment of Waste Management Practices among Residents of Owerri Municipal Imo State Nigeria.' Journal of Environmental Protection, 6, 446-456. http://dx.doi.org/10.4236/jep.2015.65043

Ahmed, K., Tanko, A. I. (2000) 'Assessment of water quality changes for irrigation in the River Hadejia Catchment.' Journal of Arid Agriculture 10: 89-94.

Ajibade, L. T. (2004) 'Assessment of water quality near River Asa, Ilorin, Nigeria.' The Environmentalist 24: 11-18.

Akali, O. T., Iorhemen, D. M., Otun J. A., and Alfa M. I. (2014), 'Provision of Sustainable Water Supply System in Nigeria: A Case Study of Wannune-Benue State.' World Journal of Environmental Engineering, 2 (1) 1-5. doi: 10.12691/wjee-2-1-1

Akin-Oriola, G. A. (2003) 'On the Phytoplankton of Awba reservoir, Ibadan, Nigeria.' Revista de Biol. 51: 1-15.

Angelakis, A. N. and Snyder, S. A. (2015) 'Wastewater Treatment and Reuse: Past, Present, and Future' Water 7 , $4887-4895$

Arimoro, F., . C.M. a. I., and . O.O. (2008) 'Effects of Industrial Wastewater on the Physical and Chemical Characteristics of a Tropical Coastal River'. Research Journal of Environmental Sciences 2 (3) 209-220

Arimoro, F.O., R.B. Ikomi and C.M.A. Iwegbue, (2007) 'Ecology and abundance of oligochaetes as indicators of organic pollution in an urban stream in Southern Nigeria.' Pak. J. Biol. Sci., 10: 446453.

Armah, A.K., S.D. Ababio and G.A. Darpaah, (2005) 'Spatial and temporal variations in water physicochemical parameters in the SouthWestern sector of the Keta Lagoon, Ghana.' Proceedings of the 14th Biennial Coastal Zone Conference, New Oceans, Louivana.

Badejo, A. A, Julius M. Ndambuki, Williams K. Kupolati, Adebola A Adekunle, Solomon A. Taiwo \& David O. Omole (2015) 'Appraisal of access to safe drinking water in southwest Nigeria', African Journal of Science, Technology, Innovation and Development, 7:6, 441-445, DOI: 10.1080/20421338.2015.1096669

Baggett, S.; Jeffrey, P. and Jefferson, B. (2006) "Risk perception in participatory planning for water reuse". Desalination, 187, 149-158.

Bahadori, A. (2014) 'Water Pollution Control'. Pollution Control in Oil, Gas and Chemical Plants 17, 119 - 165

Bakker, K. (2002) "From state to market?: water mercantilizacion in Spain". Environment and Planning A, 34, 767-790.

Brown, R. (2005) "Impediments to integrated urban stormwater management: the need for institutional reform". Environmental Management, 36 (3), 455-468.

Coombes, P.J.; Kuczera, G.; Kalma, J.D. and Argue, J.R. (2002) "An evaluation of the benefits of source control measures at the regional scale". Urban Water, 4, 307-320.

D. Mara, G. Alabaster, (2008) 'A New Paradigm for Low-Cost Urban Water Supplies and Sanitation in Developing Countries' Water Policy, 10 (2), 119-129.

Dallas, S., and Ho, G., (2005) 'Subsurface Flow Reedbeds Using Alternative Media For The Treatment Of Domestic Greywater In Monteverde, Costa Rica, Central America.' Journal of Water, Science and Technology 51(10), $119-128$.

Ekiye, E., and Zejiao, L. (2010) 'Water quality monitoring in Nigeria; Case Study of Nigeria’s industrial cities.' 
Journal of American Science 6: 22-28.

Emigilati, M.A., Ishiaku I., Usman, B.Y., Kuta, G.I. and Dangana, K. (2015) 'Assessment of Effluents Discharged from Textiles Industries in Selected Villages in Kaduna State', Nigeria. African Journal of Environmental Science and Technology, 9, 385-389.

Eynard, F., Mez, K. and Walther, J.L. (2000) 'Risk of Cyanobacterial Toxins in Riga waters (LATVIA)', Water Research Journal, 34 (11), 2979-2988.

Fane, S. and Mitchell, C. (2006) "Appropriate cost analysis for decentralized water systems". Enviro 06 conference and exhibition, May 9-11, Melbourne, Australia.

Faruqui, N. and Al-Jayyousi, O. (2002) "Greywater reuse in urban agriculture for poverty alleviation. A case study in Jordan”. Water International, 27 (3), 387-394.

Federal Republic of Nigeria (2003). Nigerian First National Communication Under the United Nations Framework. Convention on Climate change. Ministry of Environment. [online] available from $<$ http://unfccc.int/resource/docs/natc/niganc1.pdf $>$ [01/4/17]

Gleick, P.H. (2003) "Water use”. Annual Review of Environmental Resources, 28, 275-314.

Gutiérrez-Ayuso, A. (2000-2001) "Contribución al conocimiento de los aljibes hispanomusulmanes extremeños: Tipología de un ejemplo de arquitectura del agua”. Norba Arte, 7-27.

Hoek, W., (2004) A Framework for a Global Assessment of The Extent Of Wastewater Irrigation: The Need For A Common Typology. International Water Management Institute (IWMI) Bierstalpad, The Netherlands.

Idris-Nda, a., Aliyu, H.K., and Dalil, M. (2013) 'The Challenges of Domestic Wastewater Management in Nigeria: A Case Study of Minna, Central Nigeria'. International Society for Development and Sustainability [online] 2 (2) 1169-1182. available from <http://isdsnet.com/ijds-v2n2-53.pdf $>$

Idu, A.J. (2015) 'Geology \& Geophysics Threats to Water Resources Development in Nigeria.' 4 (3)

Ikomi, R.B., Iloba K.I., and Ekure, M.A. (2003). 'The physical and chemical hydrology of river Adofi at Utagbauno, Delta state, Nigeria.' Zoologist, 2: 8495.

Izonfuo, W.A., Bariweni, P., and George, D. (2013) 'Soil Contamination from Cassava Wastewater Discharges in a Rural Community in the Niger Delta, Nigeria'. Journal of Applied Science in Environmental Management 17 (2), 105-110

Kadiri, M.O. (2006) 'Phytoplankton Flora and Physicochemical attributes of some waters in the Eastern NigerDelta area of Nigeria.' Nigerian Journal of Botany, 19 (2), 188-200.

Kallis, G. and Cocossis, H. (2003) "Managing Water for Athens: From the Hydraulic to the Rational Growth Paradigms". European Planning Studies, 11, 245-261.

Konaté, S. (2012) Gestion des eaux usées domestiques dans le district de Bamako. Cas de la commune V, MSc Dissertation, University Institute of Territorial Development, Mali.

Krozer, Y.; Hophmayer-Tokich, S.; Van Meerendonk, H.; Tijsma, S. and Vos, E. (2010) Innovations in the water chain: Experiences in The Netherlands.

Langergraber, G. and Muellegger, E. (2005) “Ecological Sanitation: A way to solve global sanitation problems?". Environment International, 31, 433-444.

Lipp, E.K., Farrah, S.A. and Rose, B. (2001) 'Assessment and Impact of Microbial Fecal Pollution and Human Enteric Pathogens in a Coastal Community.' Marine Pollution Bulletin, 42, 286-293. http://dx.doi.org/10.1016/S0025-326X(00)00152-1

Mah, D.Y.S., Bong, C.H.J., Putuhena, F.J., and Said, S., (2009) 'A Conceptual Modeling Of Ecological Greywater Recycling System’ Resources, Conservation and Recycling. 53 (2009) 113-121.

Mahmood, S. and Maqbool, A. (2006) 'Impacts of Wastewater Irrigation on Water Quality and on the Health of Local Community in Faisalabad, Pakistan', Pakistan Journal of Water Resources, 10: 230270.

Nassartbaye, N. (2011) Accès à l'eau potable et à l'assainissement; quels enjeux pour la santé dans les quartiers précaires? Etude appliquée au quartier Gamkallé de la commune IV de Niamey au Niger. MSc Dissertation, Abdou Moumouni University of Niamey, Niamey.

Ogidiaka, T., 2006. 'Fish communities of Warri River at Agbarho.' Delta State, Nigeria Unpublished B.Sc. Project, 86.

Olaleye, V.F. and A.A. Adedeji, (2005) 'Water and planktonic quality of a palm oil effluent impacted river in Ondo state, Nigeria.' Int. J. Zool. Res., 1: 1520.

Olomukoro, O.J. and A.B.M. Egborge, (2003) 'Hydrobiological studies on Warri River, Nigeria Part II: Seasonal trend in the physicochemical limnology.' Trop. Freshwater Biol., 12: 923.

Olubori, J.O. (2013) 'The City of Lagos: Solid Waste Management.' International Solid Waste Association (ISWA) World Congress, Vienna, Austria.

Omenka, E. (2010) 'Improvement of Decentralized Wastewater Treatment in Asaba'. Master's Thesis, Lund University, Lund [online] (July) 8. available from <http://www.vateknik.lth.se/exjobbR/E496.pdf $>$

Onabolu, B., Jimoh, O.D., Igboro, S.B., Sridhar, M.K.C., Onyilo, G., Gege, A., and Ilya, R. (2011) 'Source to Point of Use Drinking Water Changes and Knowledge, Attitude and Practices in Katsina State, Northern 
Nigeria'. Physics and Chemistry of the Earth [online] 36 (14-15) 1189-1196. available from $<$ http://dx.doi.org/10.1016/j.pce.2011.07.038>

Osirike, B.A., (2003) Towards The Millennium Development Goals: Water Supply Management In Rural Niger Delta. 29th WEDC International Conference. Abuja. Nigeria.

Owuli, M.A. (2003) 'Assesment of impact of sewage effluents on coastal water quality in Hafnarfjordur, Iceland', The United Nations Fishery Training Program, Final Report.

Paillard, D., Dubois, V., Thiebaut, R., Nathier, F., Hogland, E., Caumette, P. and Quentine, C. (2005) 'Occurrence of Listeria sIn effluents of French urban wastewater treatment plants', Journal of Applied Environmental Microbiology, 71 11, 7562-7566.

Pandey, D.N.; Gupta, A.K. and Anderson, D.M. (2003) "Rainwater harvesting as an adaptation to climate change". Current Science, 85 (1), 46-59.

Psutka, R. Peletz, S. Michelo, P. Kelly, T. Clasen, (2011) 'Assessing the Microbiological Performance and Potential Cost of Boiling Drinking Water in Urban Zambia' Environ. Sci. Technol., 45 (14) 6095-6101.

Punmia, B.C.; Jain, A. K and Ashok, K. (2007) Invironmental Engineering - 2 Wastewater Engineering (Including Air Pollution) Laxmi Publications (D) Ltd New Delhi Madras Jalandhar Hyderabad.

Reynolds Rodney R. (2003)“Produced Water and Associated Issues," a manual for independent operator, Petroleum Technology Transfer Council.

Rotmans, J.; Kemp, R. and Van Asselt, M. (2001) "More evolution than revolution: transition management in public policy". Foresight, 3 (1), 15-31.

Roy, A.H. et al. (2008) "Impediments and solutions to sustainable, watershed-scale urban stormwater management: lessons from Australia and the United States". Environmental Management, 42 (2), 344-359.

Sadi, I.A. and Adebitan, E.O. (2014) 'Wastewater Recycling in the Hospitality Industry'. Academic Journal of $\begin{array}{lllllll}\text { Interdisciplinary } & \text { Studies } & \text { [online] } & 3 & (7) & 9-15 . & \text { available }\end{array}$ $<$ http://www.mcser.org/journal/index.php/ajis/article/viewFile/5329/5145\%5Cnhttp://mcser.org/journal/ind ex.php/ajis/article/view/5329>

Scott C, Faruqui NI, Raschid L 2004. Wastewater Use in Irrigated Agriculture. Confronting the Livelihood and Environmental Realities. From <http://www.idrc.ca/ en/ev-31595-201-1-DO_TOPIC.html > (Retrieved December 28, 2008).

Sonune, A. and Ghate, R. (2004) 'Developments in Wastewater Treatment Methods'. Desalination 167 (1-3) $55-63$

Swyngedouw, E. (2005) "Governance Innovation and the Citizen: The Janus Face of Governance-Beyond-theState”. Urban Studies, 42 (11), 1991-2006.

Tanimu, Y., Bako, S.P., and Adakole, J.A. (2011) 'Effects of Domestic Wastewater on Water Quality of Three Reservoirs Supplying Drinking Water in Kaduna State - Northern Nigeria'. Wastewater - Evaluation and Management 470

UNEP (2009) Rainwater harvesting: a lifeline for human well-being. A report prepared for UNEP by Stockholm Environment Institute.

Veil J.A., Puder M.G., Elcock D., and Redweik R. Jr. J.: “A White Paper Describing Produced Water from Production of Crude Oil, Natural Gas, and Coal Bed Methane," US DOE (January 2004) W-31-109-Eng-38.

Wakawa, R. J., Uzairu, A., Kagbu, J. A., Balarabe, M. L. (2008) 'Impact assessment of effluent discharge on physico-chemical parameters and some heavy metal concentrations in surface water of River Challawa Kano, Nigeria.' African Journal of Pure and Applied Chemistry 2: 100-106.

Wang, H., Wang, T., Zhang, B., Li, F., Toure, B., Omosa, I.B., Chiramba, T., Abdel-Monem, M., and Pradhan, M. (2014) 'Water and Wastewater Treatment in Africa - Current Practices and Challenges'. Clean - Soil, Air, Water 42 (8) 1029-1035

Water News Europe (2017) World Water Day 2017 is Aiming at Reusing Wastewater [online] available from < http://www.waternewseurope.com/world-water-day-2017-is-aiming-at-reusing-wastewater/ > [17/4/17]

Widiastuti, N., Wu, H., Ang, M., (2008) 'The Potential Application Of Natural Zeolite For Greywater Treatment.' Journal of Desalination $218(1-3) 271-281$.

Winward, G. P., Avery, L. M., Frazer-Williams, R., Pidou, M., Jeffrey, P., Stephenson, T., and Jefferson, B., (2008) 'A Study of the Microbial Quality of Grey Water And An Evaluation of Treatment Technologies for Reuse'. Journal of Ecological Engineering. 32 (2): 187 - 197. 